\title{
Fraturas, carste e cavernas nos calcários Jandaíra em Felipe Guerra, Rio Grande do Norte
}

\author{
Fractures, karst and caves in Jandaira limestones,
} Felipe Guerra, Rio Grande do Norte, Brazil

\author{
Iris Pereira Gomes ${ }^{1}$ (D), César Ulisses Vieira Veríssimo² (D), Francisco Hilário Rego Bezerra ${ }^{3}$ (D), \\ Jefferson Lima dos Santos² (D), José Ronaldo de Freitas Câmara ${ }^{4}$ (D) \\ ${ }^{1}$ Companhia de Pesquisa de Recursos Minerais - CPRM, Avenida Antônio Sales, 1.418, Dionísio Torres, CEP 60135-101, \\ Fortaleza, CE, BR (iris.gomes@cprm.gov.br) \\ 2Universidade Federal do Ceará - UFC, Departamento de Geologia, Centro de Ciências, Fortaleza, CE, BR (verissimo@ufc.br; \\ jeffgeologia@yahoo.com.br) \\ ${ }^{3}$ Universidade Federal do Rio Grande do Norte - UFRN, Departamento de Geologia, Natal, RN, BR (bezerrafh@geologia.ufrn.br) \\ ${ }^{4}$ Casa Grande Mineração LTDA., Parelhas, RN, BR (ronaldo.camara@hotmail.com)
}

Recebido em 24 de agosto de 2018; aceito em 01 de novembro de 2018

\begin{abstract}
Resumo
Condicionantes estruturais e geológicos foram estudados no lajedo do Arapuá em Felipe Guerra, oeste da Bacia Potiguar, com objetivo de avaliar sua influência no controle e na evolução de feições cársticas em carbonatos cretáceos da Formação Jandaíra. O arranjo estrutural das descontinuidades mostra a existência de quatro famílias de fraturas com direções preferenciais: NW-SE, NE-SW, N-S e E-W, as quais coincidem tanto com os principais sistemas de falhas da Bacia Potiguar como com a direção de desenvolvimento de cavernas na área de estudo. A caverna de Arapuá, principal cavidade da área, foi mapeada em escala de detalhe e realizado o levantamento estrutural das descontinuidades presentes no seu interior. As galerias principais que delimitam o contorno da caverna, as fendas e os alinhamentos de estalactites no teto, obedecem ao controle estrutural similar observado na superfície do lajedo. A simulação estocástica booleana aplicada às descontinuidades da área estudada permitiu a geração de gráficos tridimensionais que forneceram uma visão tridimensional (3D) da intensidade e da orientação espacial das estruturas em três profundidades distintas, reforçando a tendência das direções de fraturamento reconhecidas em superfície, com grande redução da ocorrência e penetratividade das direções E-W e N-S com a profundidade. $\mathrm{O}$ arranjo estrutural local coincide com o regional observado na Bacia Potiguar, configurado por um sistema de falhas extensionais que limitam altos e baixos estruturais orientados segundo NE-SW e NW-SE, herdados da fragmentação do supercontinente Gondwana e da abertura do Atlântico Sul. Pequenas falhas NE-SW com movimentação direcional dextral sugerem associação com estruturas reativadas em regime transcorrente. Entre as diferentes fácies reconhecidas nas seções da caverna de Arapuá, os mudstones e os carbonatos cristalinos correspondem às com maior desenvolvimento de porosidade secundária e de cavidades.
\end{abstract}

Palavras-chave: Fraturas; Modelagem matemática; Caverna de Arapuá; Calcários Jandaíra.

\begin{abstract}
Structural and geological conditions were studied to evaluate their influence on the control and evolution of karst features in Cretaceous carbonates of the Jandaíra Formation. The investigated area was the Arapuá limestone outcrop located in the municipality of Felipe Guerra, western part of the Potiguar Basin. The structural arrangement of the fractures shows the existence of four families with preferential strike directions: NW-SE, NE-SW, NS and E-W which coincide with the major fault systems in the Potiguar Basin, as with the direction of caves development in the study area. The Arapuá cave, main cavity of the area, was mapped in detail scale and we carried out the structural survey of existing discontinuities within it. The main galleries that define the cave's outline, the cracks and stalactites alignments on the ceiling follow the same structural control observed on the outcrop's surface. A Boolean stochastic simulation applied to the discontinuities in the studied area allowed the generation of three-dimensional graphics to provide a tridimensional (3D) view of the intensity and spatial orientation of structures in three different depths, enhancing the tendency of fracture directions recognized at the surface, with great reduction in the occurrence and quantity of the E-W and N-S oriented fractures with depth. Local structural ar-
\end{abstract}


rangement coincides with the regional one observed in the Potiguar Basin, set up by a system of extensional faults that limit structural horst and grabens oriented along NE-SW and NW-SE, inherited from the fragmentation of the supercontinent Gondwana and South Atlantic opening. Small NE-SW faults with dextral directional movement suggest association with reactivated structures in a strike-slip regime. Among the different facies recognized in cross sections of the Arapuá cave, the mudstones and crystalline carbonates correspond to those with greater development of secondary porosity and cavities.

Keywords: Fractures; Mathematical modeling; Arapuá cave; Jandaíra limestones.

\section{INTRODUÇÃO}

A circulação das águas nas rochas carbonáticas e sua dissolução são normalmente controladas pela existência de estruturas pretéritas que se alargam pela ação de águas acidificadas dissolvendo o carbonato de cálcio. Nos sistemas cársticos, a influência do controle estrutural é, muitas vezes, marcante e os mapas de caverna podem refletir essa influência nos padrões das galerias subterrâneas em rochas intensamente fraturadas (Ford e Williams, 1989; Palmer, 2007).

O município de Felipe Guerra abriga a maior concentração de cavidades naturais do Rio Grande do Norte (191 cavernas) e um patrimônio espeleológico de extrema relevância, sob o ponto de vista geológico e biológico (Cruz et al., 2010). Entre elas, destacam-se a caverna do Trapiá, maior caverna do estado, com $2.330 \mathrm{~m}$ de desenvolvimento linear, e a dolina do Xavier, maior dolina, com mais de $30 \mathrm{~m}$ de diâmetro e $20 \mathrm{~m}$ de profundidade (Bento et al., 2011).

A área-alvo da pesquisa abrange $11 \mathrm{~km}^{2}$ e está inserida no lajedo de Arapuá, centro leste do município de Felipe Guerra, onde se localizam as cavernas de Arapuá, Sabonete, pequena gruta de Arapuá, gruta da Bota e dolinas do Xavier e Xavier II (Figura 1).

Foram realizados o mapeamento geológico-estrutural na escala 1:10.000 da superfície do lajedo de Arapuá e a espeleometria da caverna de Arapuá na escala de 1:200 com objetivo de avaliar a influência das estruturas no desenvolvimento de feições cársticas superficiais e na gênese e no controle das galerias da caverna.

O estudo envolveu, ainda, análises químicas e petrográficas de estratos dos calcários da Formação Jandaíra e a aplicação de modelagem matemática booleana ao conjunto de descontinuidades (juntas e falhas) presentes na superfície e no interior do lajedo de Arapuá.

O trabalho foi desenvolvido por meio de uma parceria entre os departamentos de Geologia da Universidade Federal do Ceará (UFC) e da Universidade Federal do Rio Grande do Norte (UFRN), com o subsídio do Projeto PoroVugs, financiado pela Petrobras. Os resultados obtidos contribuíram com informações geológicas sobre a gênese da gruta de Arapuá e a propagação em profundidade das estruturas existentes na superfície do lajedo (exocarste) e sua influência no controle espacial e geométrico das feições do endocarste.

\section{METODOLOGIA}

Inicialmente, foi realizada a interpretação geológica em imagens de alta resolução do satélite Quickbird adquirida junto ao Centro Nacional de Pesquisa e Conservação de Cavernas do Instituto Chico Mendes de Conservação da Biodiversidade (CECAV/ICMBio) para a identificação de feições lineares e das principais direções dos lineamentos presentes na superfície do lajedo.

Em complemento a esses dados, foram feitos o reconhecimento e o levantamento geológico-estrutural de superfície por meio da tomada de medidas de orientação espacial, da persistência, da abertura e da profundidade dos diversos sistemas de juntas e falhas. Para a definição dos intervalos de classes dos parâmetros persistência ou continuidade e abertura foi aplicada a classificação da International Society for Rock Mechanic (ISRM, 1983). Esses dois parâmetros foram medidos com bússola brunton e trena de nylon, e a profundidade com trena a laser. Durante o levantamento de campo foi realizada a descrição das variações composicionais dos calcários em uma seção vertical da dolina Xavier II e coletadas amostras para análises químicas e estudos petrográficos. Esses dados foram correlacionados lateralmente aos estratos mapeados na caverna de Arapuá, a partir das cotas altimétricas do topo do lajedo. As análises petrográficas levaram em consideração a proporção dos constituintes ortoquímicos e aloquímicos, conforme a classificação de Dunham (1962), e permitiram a identificação de oito horizontes carbonáticos principais, com diferenças na composição, na frequência e no tamanho das cavidades observadas nos estratos.

A topografia da caverna de Arapuá seguiu a metodologia convencional dos levantamentos espeleométricos utilizando bússola sobre tripé, clinômetro e trena a laser, pelo método das bases flutuantes com pêndulo, em escala de 1:200 e com grau de precisão BCRA - 3C. No interior da caverna, foram tomadas medidas de direções de fraturas nas paredes e no teto, além das direções de alinhamentos de espeleotemas (estalactites e estalagmites). Esses dados de subsuperfície foram comparados com dados de superfície por meio do tratamento estatístico das estruturas utilizando histogramas de frequência e diagramas de rosetas.

O conjunto de dados estruturais constituído pelas informações adquiridas em imagem de satélite e em campo foi utilizado para realizar modelamento matemático empregando-se $\mathrm{o}$ 

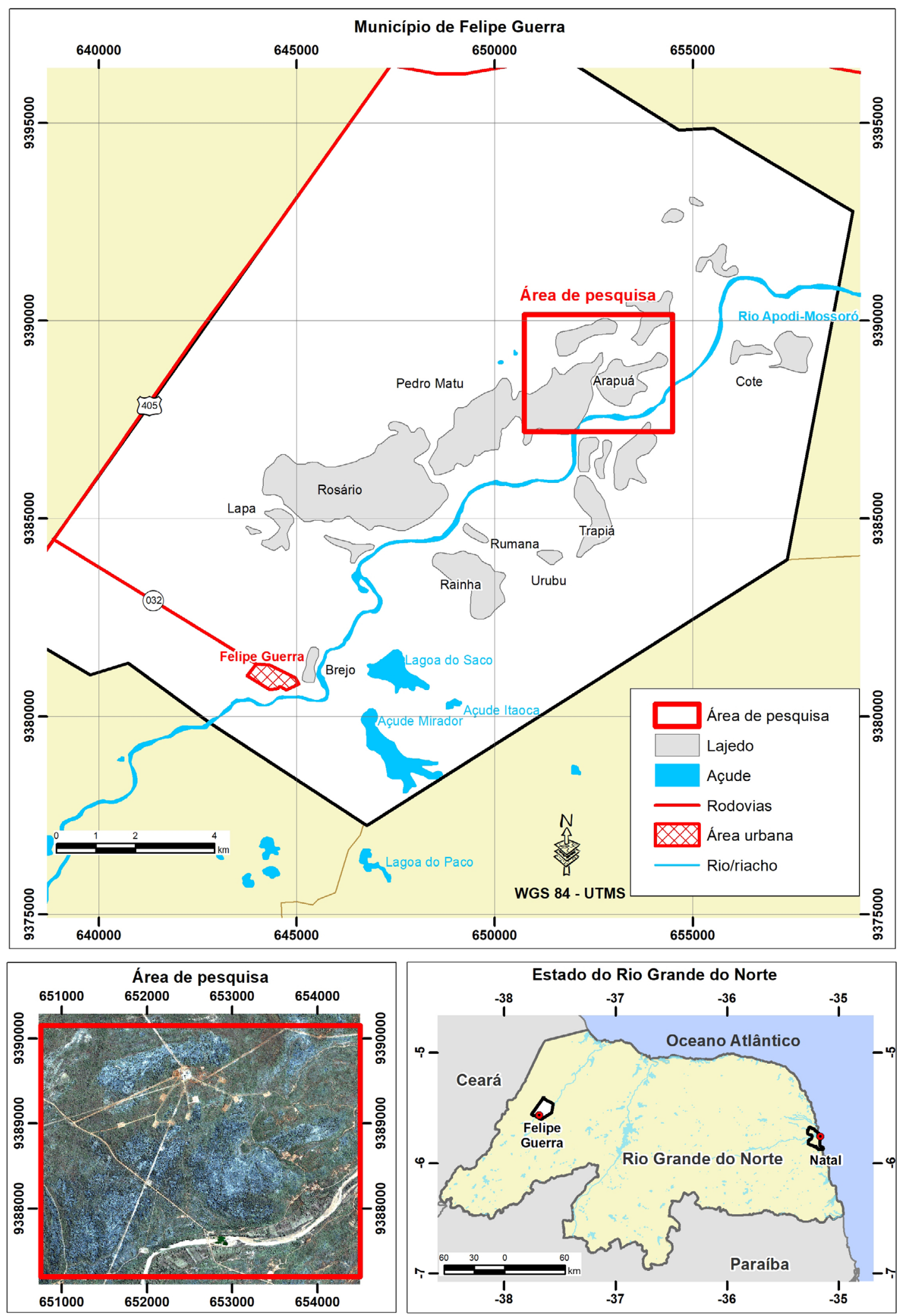

Figura 1. Mapa de localização e acesso à área de pesquisa. 
software Petbool, a partir do qual foram gerados gráficos em três dimensões, fornecendo uma visão da intensidade de fraturamento em superfície e subsuperfície da área de pesquisa.

Finalmente, após a junção das informações de campo, escritório e laboratório foi possível diferenciar quatro famílias principais de fraturas e discutir a sua influência na formação de superfícies de dissolução e no desenvolvimento de cavidades naturais no lajedo de Arapuá.

\section{ARCABOUÇO GEOMORFOLÓGICO E GEOLÓGICO REGIONAL}

O relevo no domínio do estado do Rio Grande do Norte encontra-se compartimentado em oito unidades principais: Planície Costeira, Planícies Fluviais, Tabuleiros Costeiros, Depressão Sub-Litorânea, Planalto da Borborema, Depressão Sertaneja, Chapada do Apodi e Chapada da Serra Verde (IDEMA, 2005).

O presente trabalho está inserido na unidade geomorfológica Chapada do Apodi, caracterizada por um relevo plano a suave ondulado, com cotas variando entre 10 e $150 \mathrm{~m}$ de altitude, capeada por calcários turonianos-campanianos pertencentes à Formação Jandaíra. O relevo nesse compartimento é relativamente monótono, com extensas chapadas representadas por lajedos (afloramentos calcários) segmentados por dois grandes vales abertos, de direção principal NNE-SSW, correspondendo a lineamentos estruturais do embasamento cristalino (vales dos rios Apodi-Mossoró e Piranhas Açu) e vales de menor expressão, com orientação aproximada N-S (PROASNE, 2006; Maia, 2012; Maia e Bezerra, 2012). As formas exocársticas são representadas por dolinas, lapiás e estruturas ruiniformes, enquanto no ambiente subterrâneo, ou endocarste, destacam-se cavernas ornamentadas por espeleotemas (colunas, cortinas, estalactites e estalagmites), ambos domínios produzidos pela ação geológica das águas subterrânea e superficial sobre rochas calcárias.

A área de estudo encontra-se localizada no contexto geológico da Bacia Potiguar, extremo nordeste do Brasil. Segundo Françolin e Szartmari (1987) e Matos (1992), a Bacia Potiguar é uma bacia sedimentar do tipo rift originada pela fragmentação do supercontinente Gondwana, que teve início ao final do Jurássico, estando sua origem diretamente ligada à abertura do oceano Atlântico Sul. Engloba parte dos estados do Rio Grande do Norte e do Ceará, com $48.000 \mathrm{~km}^{2}$ de área, e corresponde a uma transição entre o continente e o oceano, com porção emersa de $21.500 \mathrm{~km}^{2}$ e submersa de $26.500 \mathrm{~km}^{2}$, estendendo-se até a isóbata de $-2.000 \mathrm{~m}$. De acordo com Dantas (1998), a bacia desenvolveu-se sobre um substrato de rochas pré-cambrianas pertencentes à Província Borborema, limitando-se ao sul e a oeste com rochas do embasamento cristalino e ao norte e a leste com o oceano Atlântico (Figura 2).

O preenchimento sedimentar da bacia está relacionado com as diferentes fases de sua evolução tectônica, denominadas de fases Rifte, Transicional e de Deriva continental.

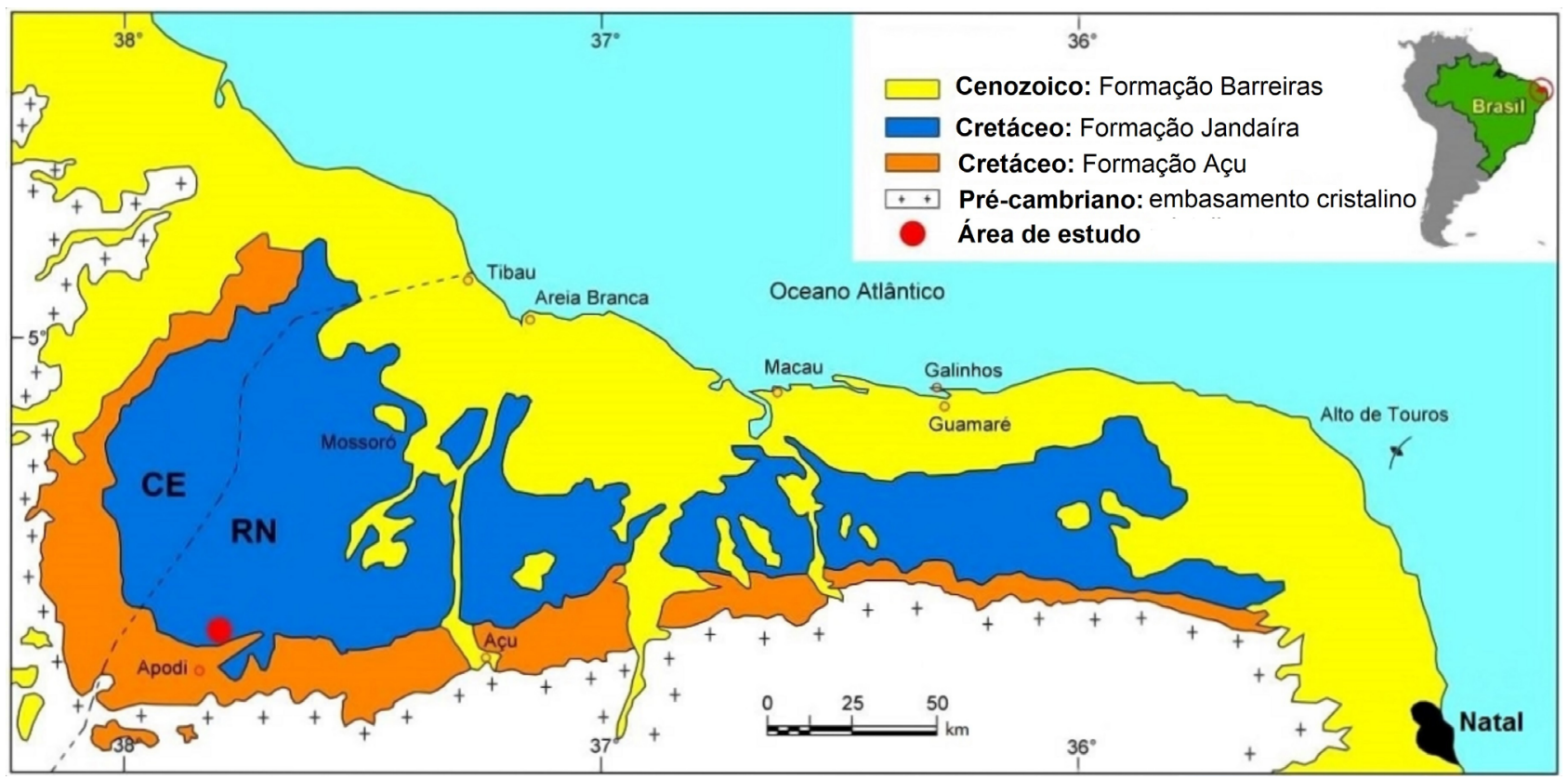

Fm.: Formação; embs.: embasamento.

Fonte: adaptado de Bertani et al., 1990.

Figura 2. Mapa geológico simplificado da Bacia Potiguar. 
Cada uma foi responsável, respectivamente, pela deposição sedimentar das megassequências continental, transicional e marinha (Chang et al., 1992).

A fase Rifte (Neocomiano/Eoaptiano) é representada pelos sedimentos das Formações Pendência (conglomerados, folhelhos lacustres e arenitos fluviodeltaicos) e Pescada (arenitos intercalados a folhelhos e siltitos). A fase Transicional (Neoaptiano/Eoalbiano) é representada pelos sedimentos da Formação Alagamar, subdividida nos Membros Upanema (arenitos fluviodeltaicos, intercalados a calcários e folhelhos), Camadas Ponta do Tubarão (folhelhos pretos e calciludito ostracoidal em sistema lagunar) e Galinhos (argilitos). A fase de Deriva Continental (Albiano/Holoceno) foi marcada por duas etapas, uma transgressiva e outra regressiva. Os calcários da Formação Jandaíra depositaram-se durante a fase transgressiva (Albiano ao Eocampaniano), que teve início com os sedimentos da Formação Açu (conglomerados, arenitos e siltitos de sistemas fluvial e deltaico-estuarino), gradando lateralmente para as Formações Ponta do Mel (calcarenitos, arenitos e calciluditos intercalados a folhelhos) e Ubarana (folhelhos, siltitos, calcilutitos, arenitos, diamictitos, conglomerados e olistolitos). Com o afogamento da Formação Açu formou-se ampla plataforma carbonática, onde se depositaram os calcarenitos com bioclástos e calciluditos da Formação Jandaíra.

A fase regressiva da bacia (Neocampaniano-Holoceno) consiste em sistemas de leques costeiros e bancos carbonáticos, representada pelas Formações Timbau (arenitos grossos e leques costeiros) e Guamaré (calcarenitos e calcilutitos de plataforma e taludes carbonáticos) (Chang et al., 1992; Pessoa Neto, 2003).

Nas fases fluviais de evolução da bacia, depositaram-se os sedimentos do Grupo Barreiras (Terciário) e depósitos eólicos, aluvionares e beachrocks (Quaternário) (Nogueira, 2004). Durante a evolução tecno-sedimentar da Bacia Potiguar, três eventos vulcânicos são registrados: Formação Rio Ceará Mirim (Jurássico-Cretáceo inf.), que corresponde a diques de diabásio toleíticos; Formação Serra do Cuó (SantonianoCampaniano), intercalada à Formação Açu, representadas por soleiras de diabásio; e Formação Macau (Terciário), intercalada aos sedimentos das Formações Ubarana, Guamaré e Tibau, constituída de necks e plugs de olivina-basalto afaníticos, e diabásios (45 a 29 Ma) (Dantas, 1998).

Regionalmente, as falhas desempenharam papel importante na evolução da Bacia Potiguar, não apenas definindo sua geometria, mas também atuando no controle da sedimentação, do transporte/migração e da acumulação de hidrocarbonetos e na configuração do relevo atual (Figura 3).

Muito embora o tectonismo atuante no Cenozoico apresente menor expressão regional em relação ao Mesozoico, eventos importantes de reativações de falhas e dobramentos de grande comprimento de onda, resultantes de esforços compressivos $\mathrm{E}-\mathrm{W}$ acompanhados de magmatismo durante $\mathrm{o}$ período Paleógeno-Neógeno, são relatados na Bacia Potiguar por diversos pesquisadores (Cremonini, 1993; Hackspacher et al., 1985; Almeida et al., 1988; Oliveira, 1993; Mizusaki et al., 2002).

Estudos mais recentes têm demostrado que a sequência pós-rifte da Bacia Potiguar foi afetada por deformação cenozoica, principalmente pela reativação dos sistemas de falhas de Afonso Bezerra e de Carnaubais com direções, respectivamente, NW-SE e NE-SW (Bezerra e Vita-Finzi, 2000; Bezerra et al., 2001, 2006, 2007, 2008; Nogueira et al., 2006; Moura-Lima et al., 2011; Maia e Bezerra, 2012, 2013, 2014).

Por meio da análise de dados de campo e de mecanismo focal de terremotos (e.g., Bezerra e Vita-Finzi, 2000; Bezerra et al., 2011; Reis et al., 2013) e estudos de paleotensões (e.g., Ferreira et al., 1998; Bezerra, 2000; Moraes Neto, 2003; Sousa et al., 2005; Nogueira et al., 2006), são registrados dois campos de tensões relacionados, respectivamente, ao Paleógeno e outro do Neógeno ao Quaternário. $\mathrm{O}$ primeiro caracterizado por esforços compressivos N-S e distensivos E-W e o segundo por compressão variando de NW-SE e distensão NE-SW na parte central e oeste da Bacia Potiguar, e compressão E-W com distensão N-S na porção leste da bacia.

O segundo campo de tensões coincide com o campo neotectônico proposto por diversos autores (Ferreira et al., 1998; Bezerra, 2000; Moraes Neto, 2003; Moura-Lima et al., 2011).

Pesquisas recentes no lajedo do Rosário, situado a sudoeste de Arapuá, realizadas a partir de análises de imagens de sensores orbitais e de veículo aéreo não tripulado (VANT), registram a existência de falhamentos transcorrentes influenciando no controle estrutural de cavernas (Santos, 2015; Carneiro et al., 2015).

\section{GEOLOGIA ESTRUTURAL}

\section{Análise geométrica e descritiva}

A análise das imagens de satélite e o levantamento geológico-estrutural de superfície levaram à diferenciação de quatro conjuntos ou famílias de juntas $\left(\mathrm{J}_{1}, \mathrm{~J}_{2}, \mathrm{~J}_{3} \mathrm{e} \mathrm{J}_{4}\right)$ que, por ocorrerem de maneira bastante expressiva em todos os segmentos do lajedo de Arapuá, sugerem origem tectônica (Figuras 4A e 5A). Essas descontinuidades sistemáticas correspondem, em sua maioria, a fraturas de extensão com planos verticais, sem movimentação aparente, representadas por fraturas abertas, resultado do afastamento das paredes laterais ou por vezes preenchidas por calcita.

Além dos sistemas de juntas tectônicas, são reconhecidas juntas estilolíticas geradas pela dissolução por pressão de 
minerais de calcita, mostrando aspecto suturado, bem como pequenas falhas de rejeito direcional. Em campo, foram reconhecidos estilólitos tanto perpendiculares ao plano de acamamento sedimentar $\left(\mathrm{S}_{0}\right)$ como paralelos a este. Nos primeiros, a disposiçãoo perpendicular ao plano de acamamento das estruturas estilolíticas sugere origem tectônica, relacionada a um campo de tensão principal horizontal próximo a N-S (Figura 4B). No segundo caso, mais frequente, ligados à dissolução por pressão e gerados pela compactação e pela diagênese dos sedimentos carbonáticos (Figura 4C).

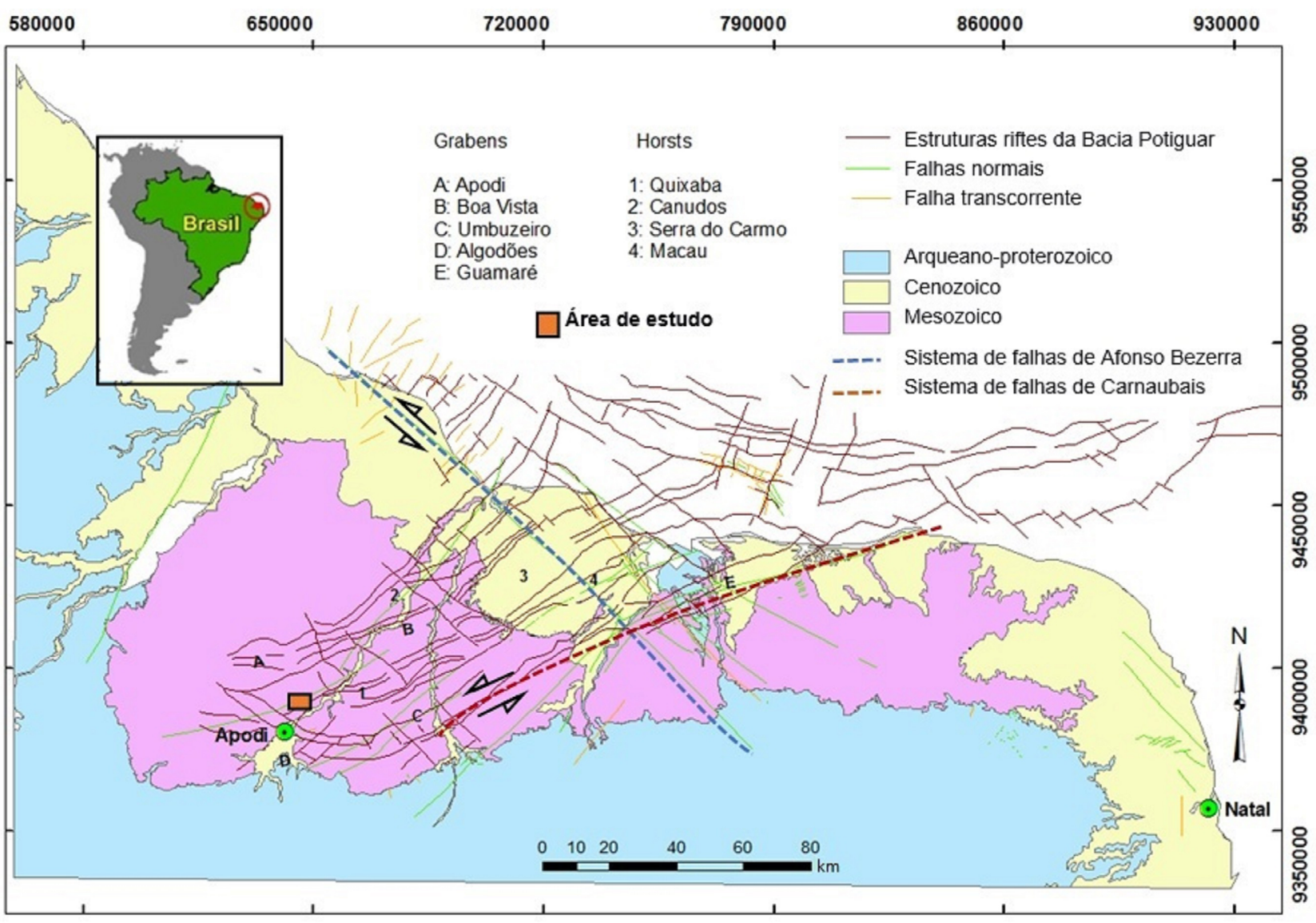

Fonte: modificado de Hackspacher et al., 1985; e Angelim, 2006.

Figura 3. Mapa estrutural da porção continental da Bacia Potiguar ilustrando sistema de falhamentos regionais NE e NW e localização da área de pesquisa.

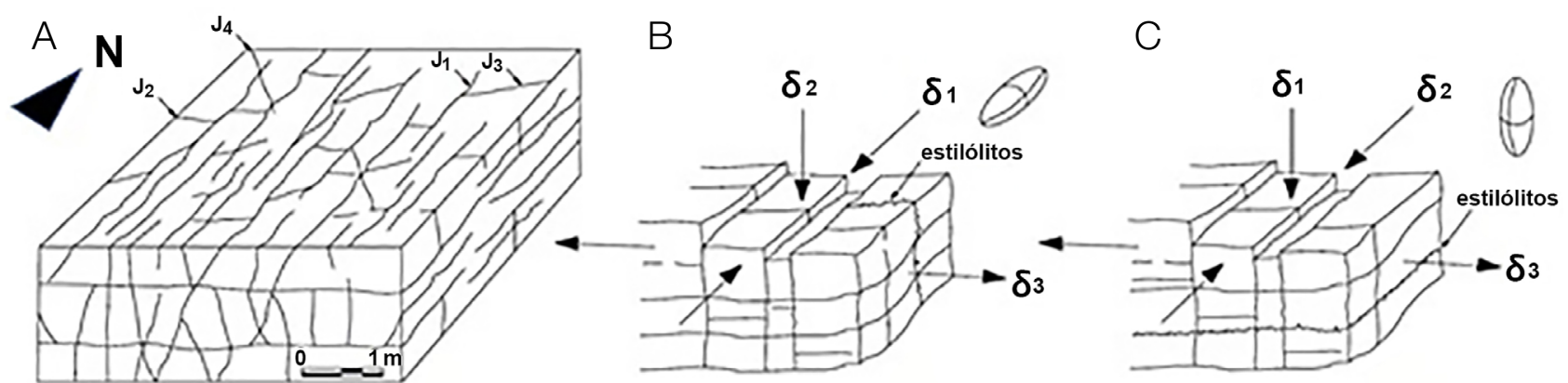

Figura 4. (A) Esquema com as quatro famílias de juntas sistemáticas $\left(J_{1}, J_{2}, J_{3}\right.$ e $\left.J_{4}\right)$ que se cruzam e a relação entre elipsoides de tensão, fraturas de extensão e estilólitos $(B)$ perpendiculares e (C) paralelos à estratificação. 
Outras fraturas de origem não tectônica (juntas ou diaclases) são representadas por gretas de contração formadas pela retração do material sedimentar muito fino (mudstones) por meio da perda de água por evaporação subaérea (Figura 5B).

As fraturas de origem tectônica (juntas tectônicas) foram classificadas, segundo sua orientação espacial, como $\mathrm{J}_{1}(\mathrm{~N}-\mathrm{S})$, $\mathrm{J}_{2}(\mathrm{E}-\mathrm{W}), \mathrm{J}_{3}(\mathrm{NE}-\mathrm{SW})$ e $\mathrm{J}_{4}(\mathrm{NW}-\mathrm{SE})$ (Figura 6A); das quais as $\mathrm{J}_{3}$ são as de caráter mais contínuo, com comprimentos superiores a $20 \mathrm{~m}$. Os outros três grupos $\left(\mathrm{J}_{1}, \mathrm{~J}_{2}\right.$ e $\left.\mathrm{J}_{4}\right)$ são menos persistentes, com a maior parte das fraturas variando de 1 a $3 \mathrm{~m}$ de comprimento (Figura 6B). O estudo mostra, ainda, que nas juntas $\left(\mathrm{J}_{3}\right)$ predominam as classes muito largas a extremamente largas em termos de abertura (Figura 7). Na classe de juntas compactas ou fechadas, a família $J_{1}$ predomina sobre a $\mathrm{J}_{3}$. As Figuras 8 e 9 ilustram a sistemática de campo de tomada de medida dos parâmetros comprimento e abertura das juntas.

A medição da abertura foi efetuada a cada metro ao longo dos planos das descontinuidades, de uma extremidade a outra, fazendo-se uma média dos valores obtidos (Figura 8B).
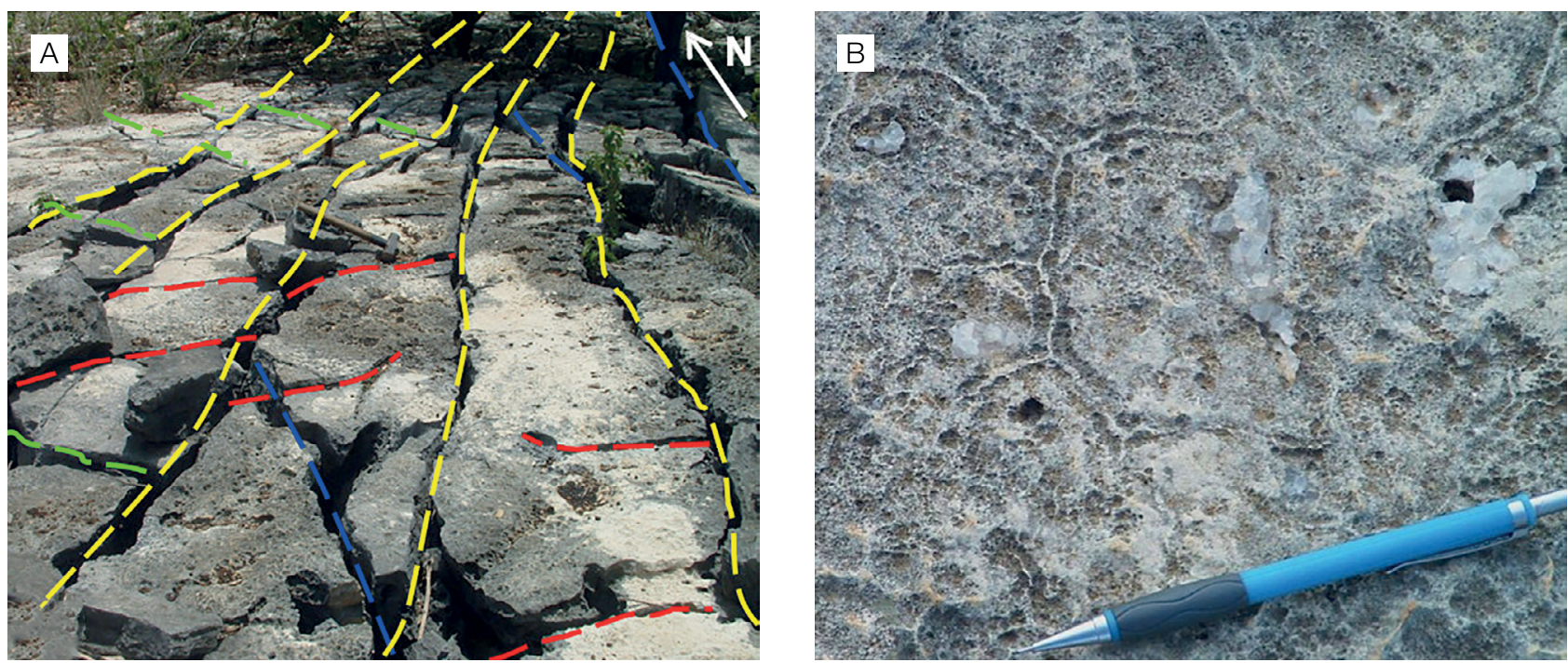

Figura 5. (A) Sistema de fraturas tectônicas sem movimento aparente, evidenciado por juntas abertas, resultado do afastamento das paredes das fraturas. Ocorrem na área tanto juntas persistentes, com comprimento excedente aos limites de exposição da rocha, como não persistentes, com terminações em outras descontinuidades; (B) juntas não tectônicas representadas por gretas de contração.

A

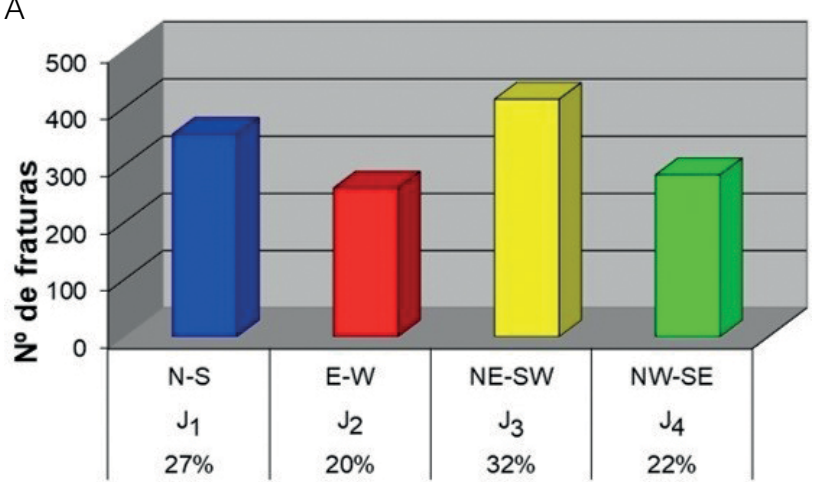

B

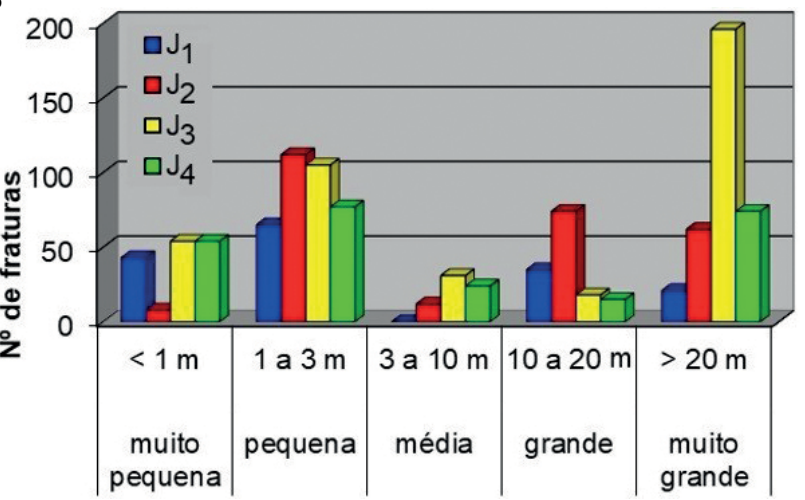

Figura 6. (A) Histograma com porcentagem de frequência das orientações espaciais das juntas tectônicas; (B) histograma de classificação do comprimento das juntas,mostrando que estas apresentam tamanhos bastante variáveis, com destaque para a família $\mathrm{J}_{3}$, com maior concentração na categoria "muito grande". A classificação segue classes de comprimento propostas pela International Society for Rock Mechanics (1983). 
O parâmetro profundidade analisado para as fraturas foi medido diretamente com trena. Assim como no parâmetro abertura, os valores de profundidade correspondem à média aritmética de 3 a 4 medidas tomadas ao longo do plano da descontinuidade. As profundidades variam de pouco menos de $1 \mathrm{~m}$ até $11 \mathrm{~m}$. As direções preferenciais

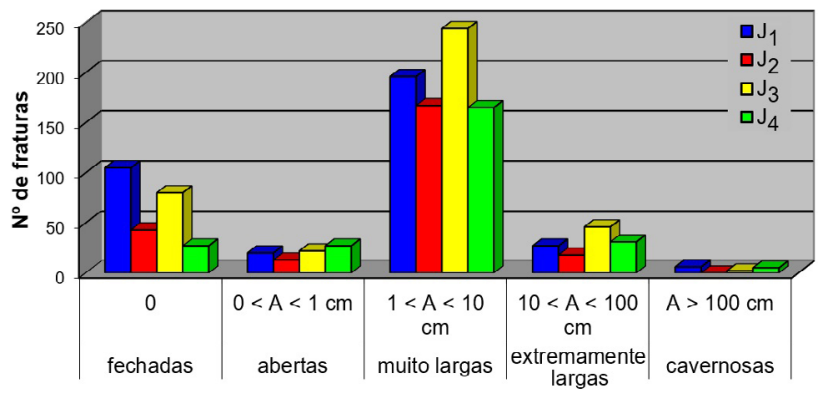

ABERTURA

Figura 7. Histograma com as classes de abertura encontradas na área, com maior concentração na categoria "muito larga" e maior quantidade de fraturas representada pela família $\mathrm{J}_{3}$.
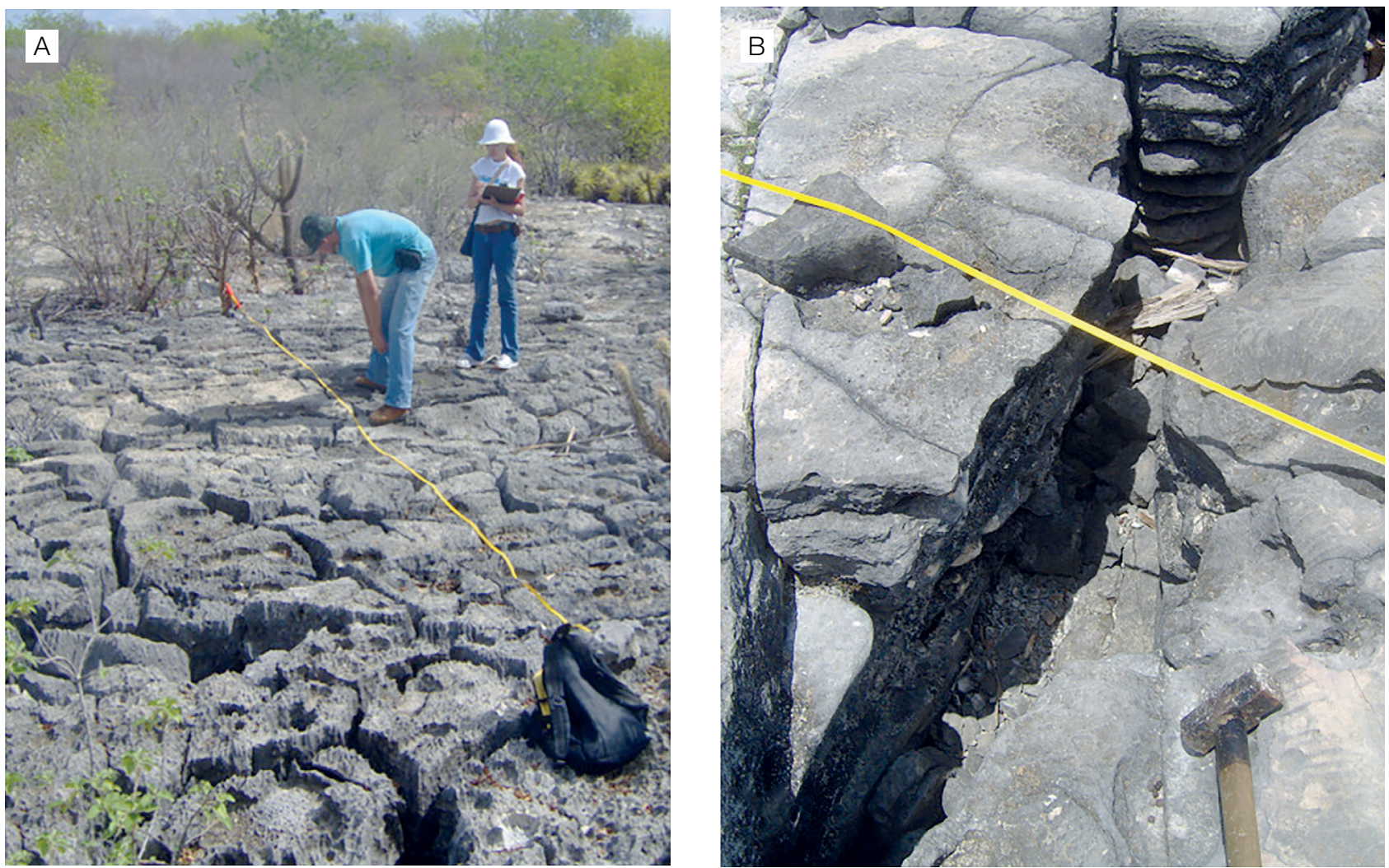

Figura 8. (A) e (B) Levantamento sistemático do parâmetro abertura em juntas tectônicas no lajedo de Arapuá. medidas na superfície do lajedo correspondem a N-S, NW-SE, NE-SW e E-W.

Quando se correlaciona o parâmetro profundidade com a orientação espacial das fraturas, observa-se que as juntas $\mathrm{J}_{2}$ são superficiais, a maior parte das juntas $\mathrm{J}_{1}(\mathrm{~N}-\mathrm{S})$ enquadra-se na categoria de profundidade "pequena", enquanto as $\mathrm{J}_{3}$ (NE-SW) e $\mathrm{J}_{4}$ (NW-SE) são classificadas como de profundidade "média a muito profunda" (Tabela 1 e Figura 10).

As estruturas orientadas NE-SW, em comparação com as demais, correspondem às maiores em todos os parâmetros analisados (comprimento, profundidade e abertura). Além de exibirem grandes extensões, também atingem profundidades expressivas, normalmente superiores a $10 \mathrm{~m}$, atravessando vários estratos carbonáticos. De acordo com o comprimento modal do traço sugerido pela ISRM (1983), as juntas $\mathrm{J}_{3}$ (NE-SW) na área estudada variam de 25 a $130 \mathrm{~m}$, enquadrando-se todas na categoria de persistência muito grande (>20 m), e apresentam abertura variando de $20 \mathrm{~cm}$ até mais que $4 \mathrm{~m}$, definidas como muito abertas e cavernosas.

Registros de indicadores cinemáticos com movimentação sinistral foram reconhecidos em planos de descontinuidades orientadas NE-SW, por meio da formação de brechas 
em arranjos de veios de extensão escalonados (Figura 11). Esses elementos somados à existência de estilólitos em planos perpendiculares ao acamamento sedimentar são indicativos de um regime tectônico do tipo transcorrente, caracterizado por planos com mergulhos verticais, eixos de tensão máxima $\left(\sigma_{1}\right)$ e mínima $\left(\sigma_{3}\right)$ horizontais e movimento relativo paralelo ao plano de falha.

A análise dos dados estruturais levantados em campo foi integrada com a interpretação de imagem de satélite Quickbird de elevada resolução (até $60 \mathrm{~cm}$ ). Na área, esses elementos são, em geral, constituídos por segmentos retilíneos ou suavemente curvilíneos, por vezes escalonados, com comprimento individual da ordem de dezenas de metros. O tratamento integrado dos lineamentos mapeados e interpretados permitiu delinear quatro direções principais relacionadas a fraturas (falhas e juntas tectônicas), havendo maior destaque para as NE-SW, NW-SE e N-S (Figura 12). Lineamentos com direção E-W têm menor participação no traçado dos sistemas.

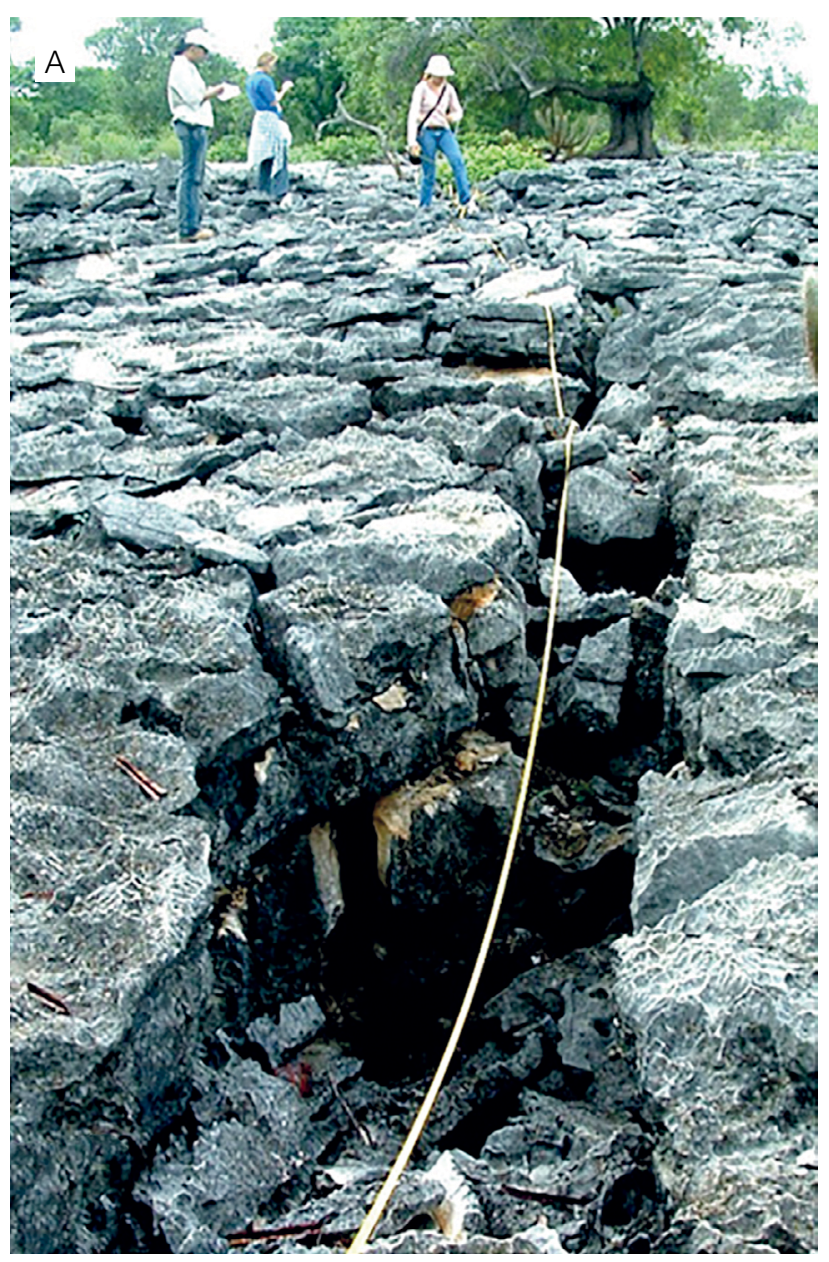

\section{Modelagem booleana}

Os conceitos aplicados ao tratamento sistemático da lógica denominada de Álgebra Booleana foram introduzidos pelo matemático inglês Boole (1854 apud Mendelson, 1977). Diferentemente da álgebra ordinária, em que as variáveis podem assumir valores no intervalo $(-\infty ;+\infty)$, as variáveis booleanas só podem assumir um número finito de

Tabela 1. Classes de profundidade segundo a International Society for Rock Mechanics (1983).

\begin{tabular}{cc}
\hline Profundidade $(\mathbf{m})$ & Descrição \\
\hline$\leq 1$ & Pequena \\
$1<a \leq 2$ & Média \\
$2<a \leq 4$ & Profunda \\
$>4$ & Muito profunda \\
\hline
\end{tabular}

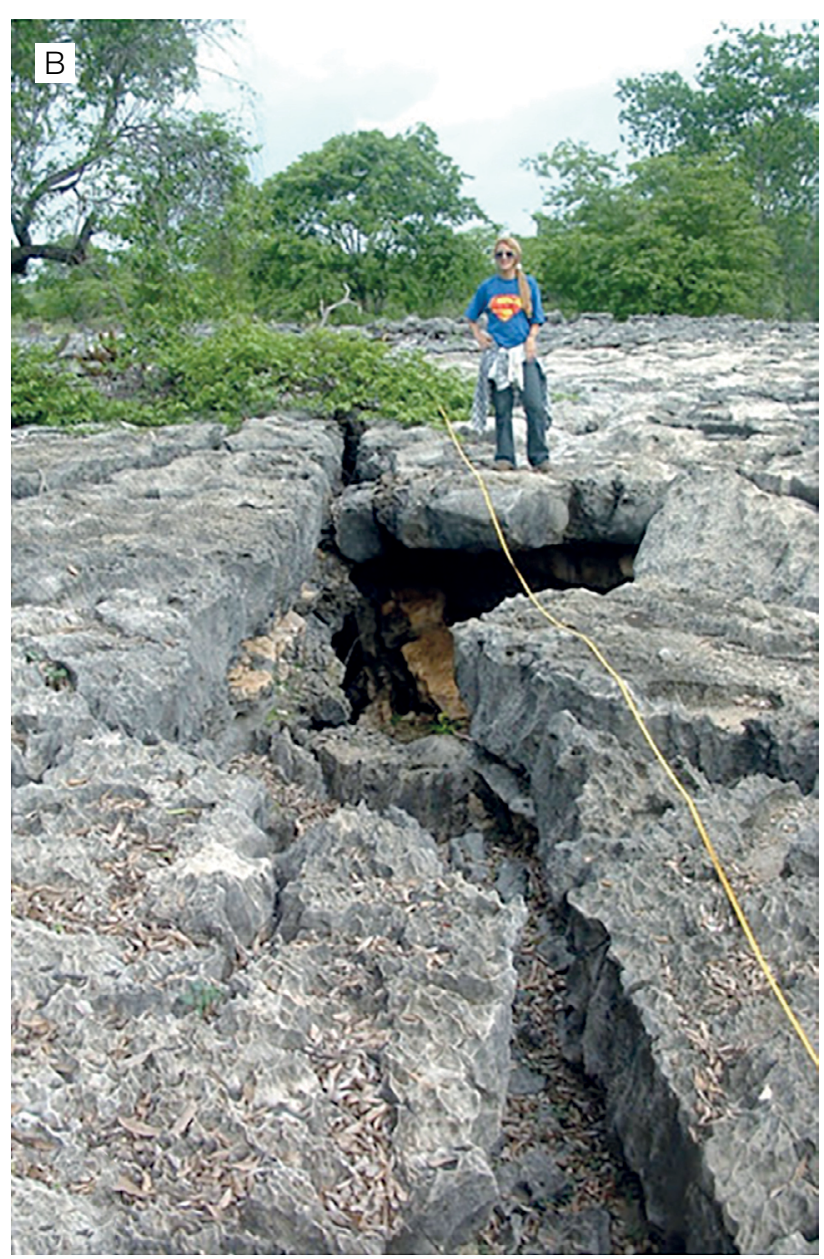

Figura 9. (A) e (B) Levantamento sistemático do parâmetro persistência ou continuidade de juntas $\mathrm{J}_{3}$ (NE-SW) controlando a formação de ravinas e abrigos no lajedo de Arapuá. 


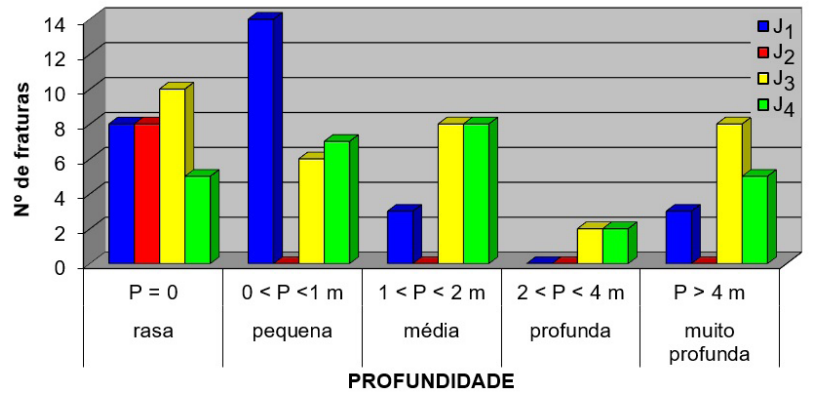

Figura 10. Histograma com a correlação entre a profundidade e a orientação espacial das fraturas. Observam-se as seguintes informações: as poucas fraturas de direção E-W possuem valores inferiores a $1 \mathrm{~m}$ de profundidade; a maior parte das juntas de direção N-S enquadra-se na categoria de profundidade "pequena"; a maior parte das juntas de direção NE-SW e NW-SE classifica-se como de profundidade "média"; e NESW correspondem à classe de juntas "muito profunda", seguidas das NW-SE. valores. Na álgebra booleana, é necessário que os planos de informação (evidências) representem apenas duas classes (padrão binário), e para a integração de planos de informação binários são utilizados os ponderadores lógicos " $E$ ”, "OU”, "Exclusivo OU (XOR)" e "NÃO", que determinam se uma hipótese satisfaz ou não a uma particular condição. Em planos de informação com representação temática, a generalização é obtida por meio de uma reclassificação das diferentes classes para "favorável" e "não favorável" (Burrough e McDonnell, 1998).

No modelo booleano de simulação estocástica é adotada a ideia intuitiva de união de objetos independentes localizados aleatoriamente e, embora não haja interação entre eles, pode haver a sobreposição (Lantuéjoul, 1995).

O modelo booleano orientado a objetos, na terminologia matemática da área de geometria estocástica, pertence à classe dos Point Process, definido mais precisamente como Random Closed Set (RACS), cuja distribuição no espaço segue a lei de probabilidade de Poisson, ou seja, quando o
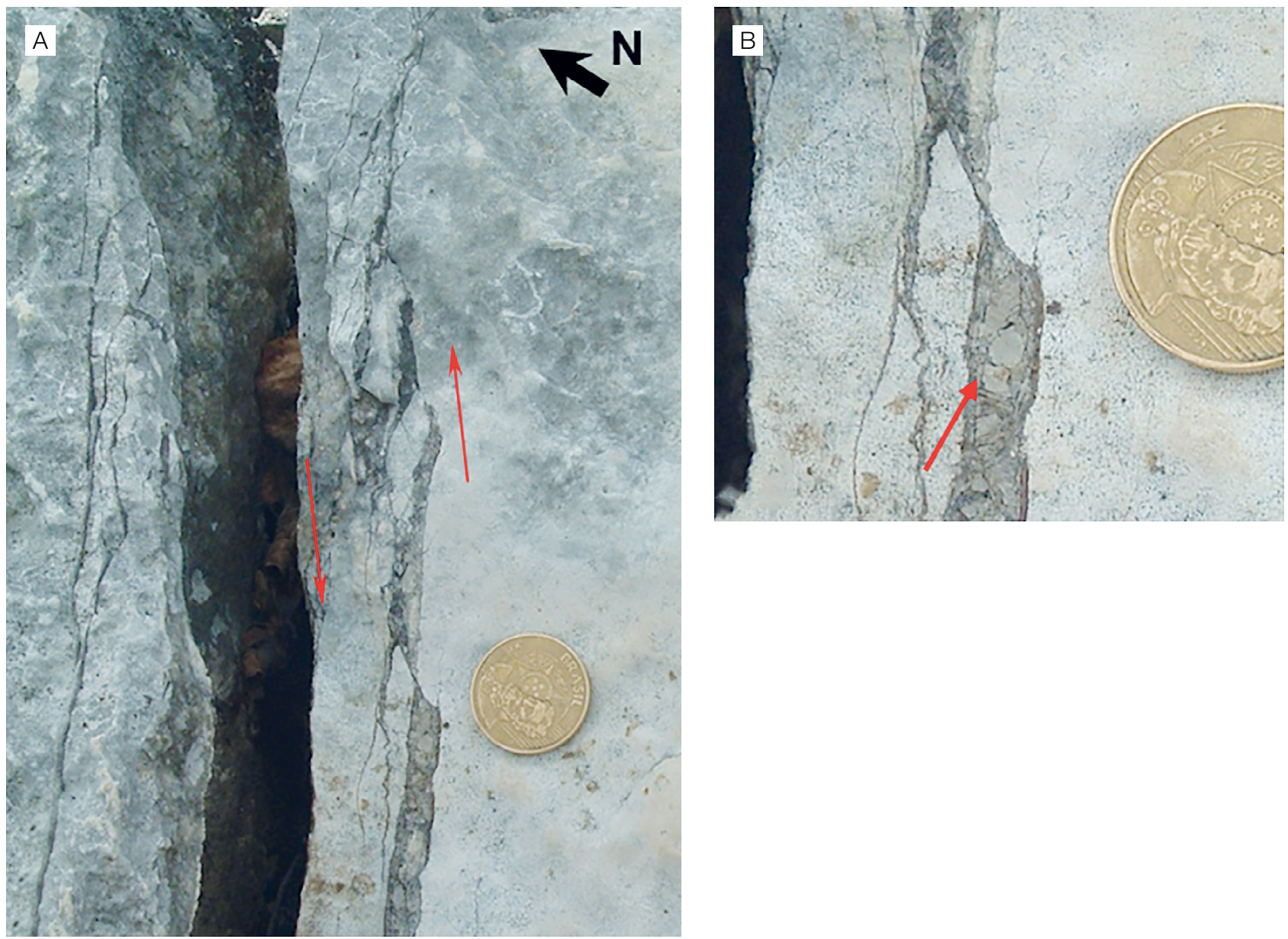

Figura 11. (A) Conjunto de veios de extensão escalonados sugerindo falha transcorrente NE-SW com movimentação sinistral; (B) detalhe do caráter brechado do veio. 
número de unidades de interesse em um dado volume é distribuído de maneira aleatória e independente (Poletto, 1996).

Ao conjunto sistemático de juntas e falhas levantadas no lajedo de Arapuá foi aplicado modelamento matemático baseado em simulação estocástica booleana, por meio do software Petbool, na Pontifícia Universidade Católica do Rio de Janeiro (PUC-Rio).
A principal característica do software é a construção de cenários tridimensionais a partir da medida dos parâmetros geométricos das descontinuidades, cujo arranjo configura a heterogeneidade das estruturas geológicas. Essa metodologia tem sido muito aplicada em reservatórios da Bacia Potiguar e da Bacia de Campos, em que métodos matemáticos envolvendo geologia, geofísica e engenharia do petróleo
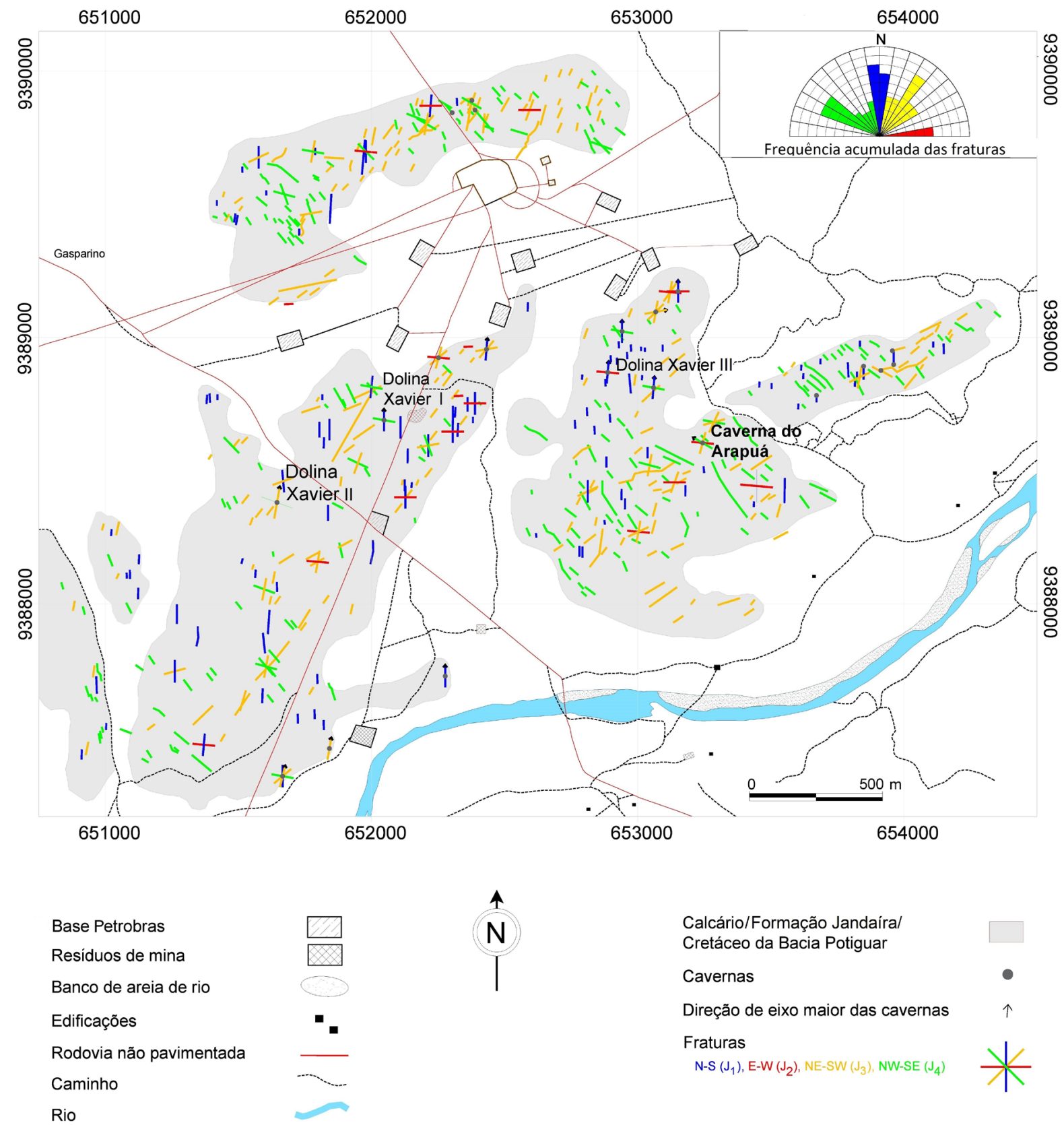

Figura 12. Lineamentos mapeados e interpretados no lajedo de Arapuá e entorno, ilustrando direções das principais famílias de juntas e falhas existentes nos afloramentos calcários. 
são usados para caracterização de reservatórios ideais à produção de óleo e gás (Lanzarini et al., 1997).

Os parâmetros analisados na modelagem foram a profundidade das juntas e das falhas, o comprimento e o ângulo em relação ao norte. A partir da modelagem booleana, gráficos tridimensionais forneceram uma visão da intensidade de fraturamento em superfície e subsuperfície do conjunto de rochas carbonáticas da área de pesquisa, destacando a tendência de três direções, NW-SE, NE-SW e N-S (Figura 13).

Observou-se, igualmente, que o número de fraturas diminui com a profundidade, em que as mais superficiais predominam nas direções $\mathrm{E}-\mathrm{W}$ e N-S ; enquanto as mais profundas incluem as NE-SW e NW-SE (Figuras 13 e 14).

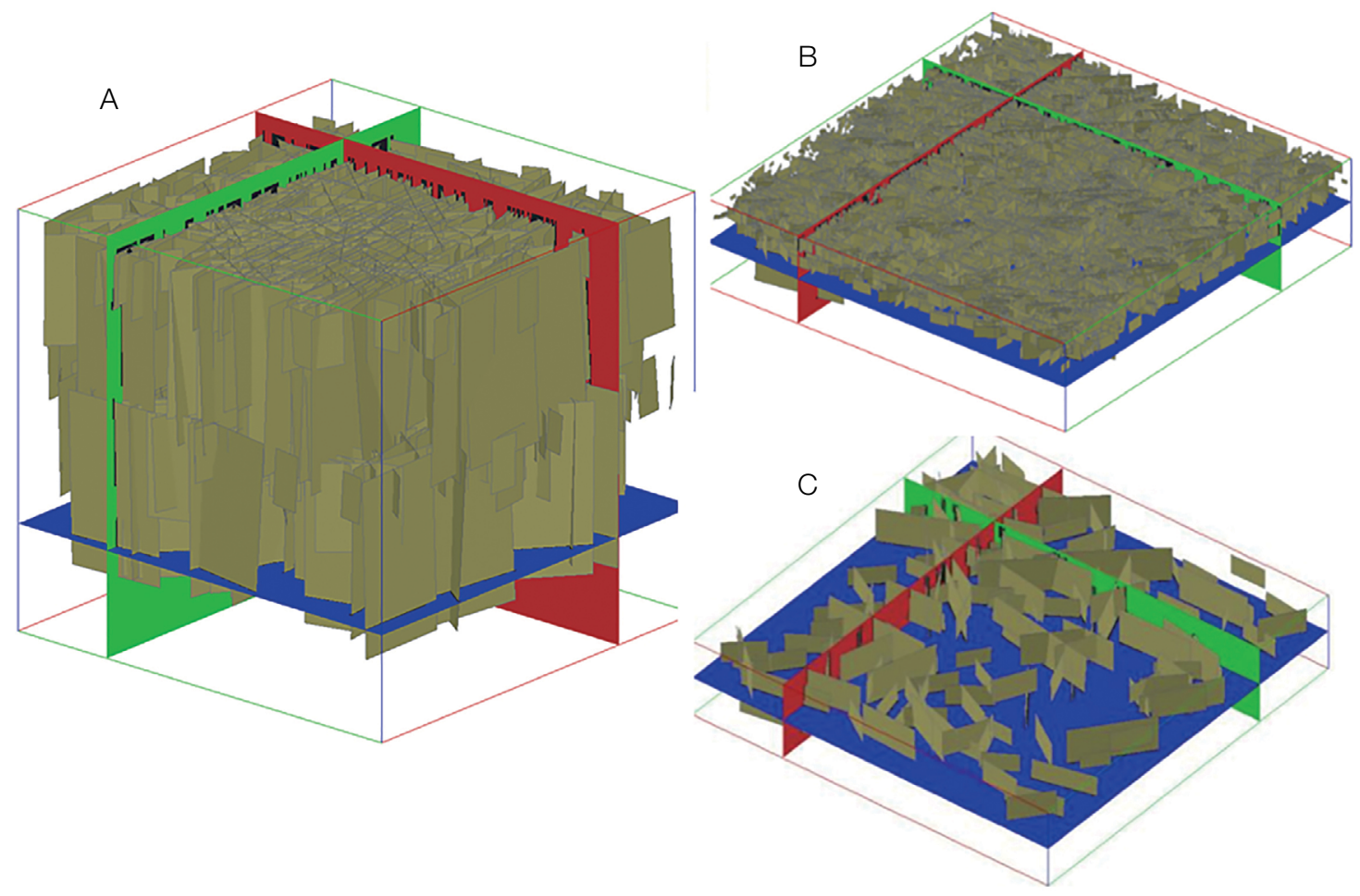

Figura 13. (A) Modelo tridimensional gerado pelo software Petbool para juntas e falhas do lajedo de Arapuá; (B) intensidade de fraturamento em superfície; $(C)$ redução do faturamento em profundidade.
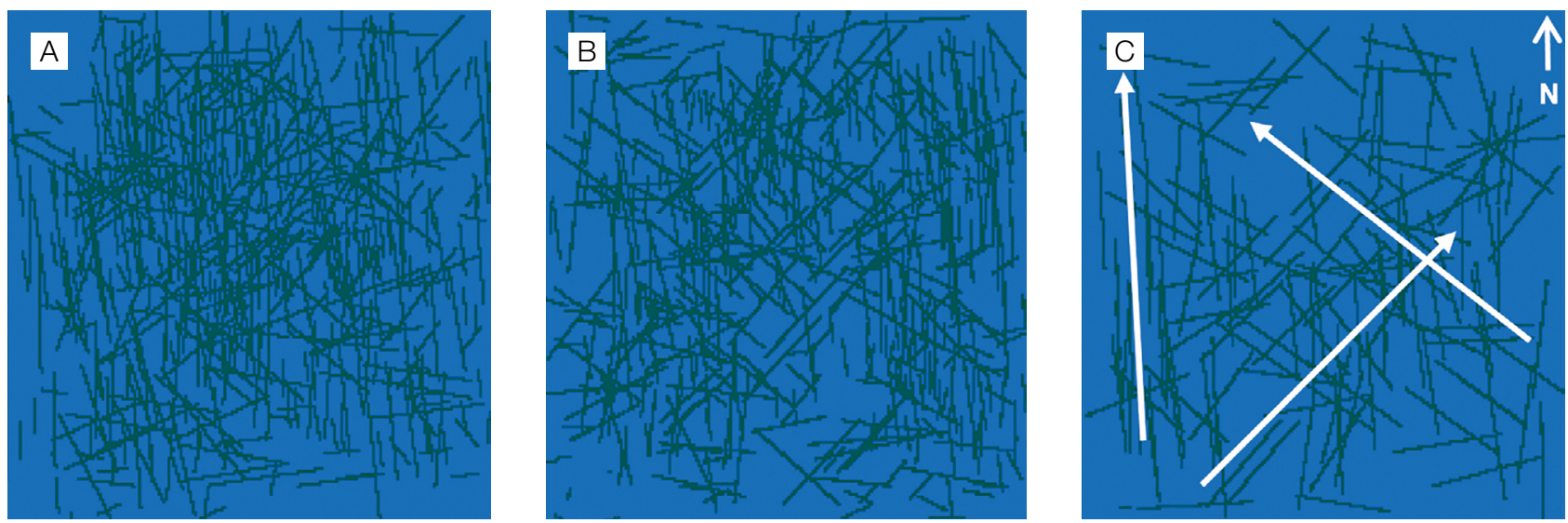

Figura 14. Simulação do plano horizontal $X Y$, em diferentes profundidades. (A) Topo (superfície), em que predominam fraturas de pequena profundidade de direção N-S; (B) ao centro, porção intermediária; (C) base, representada por fraturas (juntas e falhas) muito profundas ao longo das três direções preferenciais: NW-SE, NE-SW e N-S. 


\section{CARACTERIZAÇÃO DAS ROCHAS CARBONÁTICAS}

Análises químicas foram realizadas em nove níveis diferentes do calcário Jandaíra na dolina Xavier II, situada a oeste da caverna de Arapuá. Os resultados mostram a natureza calcítica dos calcários, apresentando teores de carbonato de cálcio $\left(\mathrm{CaCO}_{3}\right)$, em média, de $97,9 \%$ e de carbonato de magnésio $\left(\mathrm{MgCO}_{3}\right)$ de apenas $1 \%$, com o restante representado por resíduos insolúveis (Tabela 2).

As análises petrográficas confirmam a composição química simples e o caráter monominerálico dos calcários diferindo, entretanto, em seus aspectos texturais e componentes originais. Foram identificados nove horizontes carbonáticos principais, com diferenças na proporção dos constituintes ortoquímicos e aloquímicos, segundo o critério de classificação de Dunham (1962). As variações faciológicas identificadas foram classificadas em wackestone, paskstone, mudstone e carbonato cristalino. Dos oito horizontes analisados, quatro deles mostram feições macroscópicas e microscópicas de dissolução contendo cavidades que obedecem ao controle litoestratigráfico e referem-se a estratos classificados como mudstones ou carbonatos cristalinos. Os wackestones $\mathrm{e}$ packstones correspondem a níveis distintos, representando o teto e a base dos níveis cavernosos. Os níveis situados entre as profundidades de 6,2 a 5,5 $\mathrm{m}\left(\mathrm{N}_{2}\right), 4,1$ a $3,6 \mathrm{~m}\left(\mathrm{~N}_{5}\right)$ e 0 a $1 \mathrm{~m}\left(\mathrm{~N}_{9}\right)$, correspondem a mudstones, respectivamente, peloidais, bioclásticos e dolomitizados, em que o último coincide como a zona de maior desenvolvimento da caverna de Arapuá (Figura 15).

Macroscopicamente, o nível $\mathrm{N}_{2}$ (mudstone peloidal) é constituído de calcário maciço de cor cinza a creme, contendo porções porosas intemperizadas preenchidas por material argiloso (Figura 16A). A análise microscópica do nível

Tabela 2. Análises químicas de amostras do calcário Jandaíra coletadas em camadas (estratos) de seção vertical da dolina Xavier II, situada a cerca de $1,5 \mathrm{~km}$ a oeste da caverna de Arapuá.

\begin{tabular}{lcccc}
\hline Amostra & $\mathbf{R}$ & $\mathbf{R}_{\mathbf{2}} \mathbf{O}_{3}$ & $\mathbf{C a C O}_{3}$ & $\mathbf{M g C O}_{3}$ \\
\hline $\mathrm{N}_{9}(0$ a $1,0 \mathrm{~m})$ & 0,2 & 0,1 & 98,9 & 0,8 \\
$\mathrm{~N}_{8}(1,0$ a $2,3 \mathrm{~m})$ & 0,7 & 0,3 & 98,2 & 0,8 \\
$\mathrm{~N}_{7}(2,3$ a 3,0 m) & 1,7 & 0,4 & 96,6 & 1,3 \\
$\mathrm{~N}_{6}$ (3,0 a 3,6 m) & 0,8 & 0,2 & 98,2 & 0,8 \\
$\mathrm{~N}_{5}$ (3,6 a 4,1 m) & 0,9 & 0,1 & 98,0 & 1,0 \\
$\mathrm{~N}_{4}$ (4,1 a 4,8 m) & 1,2 & 0,3 & 97,5 & 1,0 \\
$\mathrm{~N}_{3}$ (4,8 a 5,5 m) & 0,7 & 0,3 & 98,2 & 0,8 \\
$\mathrm{~N}_{2}$ (5,5 a 6,2 m) & 0,7 & 0,3 & 98,2 & 0,8 \\
$\mathrm{~N}_{1}(6,2$ a $7,5 \mathrm{~m})$ & 0,9 & 0,5 & 97,1 & 1,5 \\
Média & 0,9 & 0,3 & 97,9 & 1,0 \\
\hline
\end{tabular}

RI: resíduo insolúvel; $\mathrm{R}_{2} \mathrm{O}_{3}$ : óxidos compostos; $\mathrm{CaCO}_{3}$ : carbonato de cálcio; $\mathrm{MgCO}_{3}$ : carbonato de magnésio.
$\mathrm{N}_{7}$ mostra que a rocha é formada por $98 \%$ de matriz deposicional; $2 \%$ de cimento composto de calcita em mosaico, por vezes totalmente substituído por dolomita e preenchendo localmente espaços porosos (Figuras 16B e 16C). Apresenta apenas 1\% de constituintes dispersos, representados por miliolídeos $(10 \%)$, intraclastos $(10 \%)$ e peloides $(80 \%)$. A porosidade ocorre no cimento alterado, evoluindo para vugs (Figura 16C).

O nível $\mathrm{N}_{5}$ (mudstone bioclástico) possui aproximadamente $70 \mathrm{~cm}$ de espessura, cor creme clara e aspecto cavernoso, com cavidades que podem atingir dimensões próximas a $50 \mathrm{~cm}$ (Figura 16D). A maior parte da rocha (cerca de $90 \%$ ) é formada por uma matriz deposicional e síltica, com recristalização secundária de calcita e infiltrações de argila em alguns pontos associadas a vugs (Figura 16E). O cimento representa apenas $3 \%$ da rocha, constituído de calcita em mosaico micro a mesocristalino, algumas vezes quase totalmente substituído por dolomita. Em seção delgada, apresenta poucos grãos, com tamanho médio da ordem de $0,3 \mathrm{~mm}$, cujo contato, seleção e empacotamento são indefinidos. Seus constituintes correspondem a $7 \%$ da rocha, e são representados por foraminíferos miliolídeos $(60 \%)$ (Figura 16F), peloides (33\%), gastrópodes $(<1 \%)$, ooides $(2 \%)$ e intraclastos $(5 \%)$.

O nível $\mathrm{N}_{9}$ (mudstone dolomitizado), situado a cerca de $7 \mathrm{~m}$ abaixo da superfície, corresponde ao nível inferior estudado, ao qual estão associadas as maiores cavidades do lajedo, incluindo a caverna de Arapuá. Nesse nível, encontram-se tanto feições freáticas bem desenvolvidas, materializadas por galerias com seções apresentando formato semicircular, como vadosas, em que ocorrem diversos tipos de espeleotema nas paredes, nos tetos e no piso das galerias e salões, representados por estalactites, estalagmites, cortinas, colunas etc. Nesse nível, predomina uma textura cavernosa, com matriz maciça de cor creme-clara e poros preenchidos por material argiloso vermelho-amarelado (Figura 17A). Petrograficamente, é constituído de intraclastos e miliolídeos (1\%) variando entre 0,3 e $1,0 \mathrm{~mm}$ em matriz deposicional $(95 \%)$ e cimento de calcita em mosaico mesocristalino (2\%) localmente dolomitizada. Observam-se, ainda, argilas, limonitas e cristalização secundária de calcita em geodos e fraturas. A porosidade ocorre entre os grãos de calcita ou vugs evoluindo do cimento (Figuras 17B e 17C).

Outro nível cavernoso $\left(\mathrm{N}_{7}\right)$ situa-se entre 2,3 e 3,0 m de profundidade e corresponde ao calcário cristalino de cor creme-amarelada a avermelhada, muito poroso e constituído de cimento exclusivamente de calcita em mosaico médio, com alguns cristais isolados de dolomita (Figuras 17D a 17F). Ao microscópio, esse nível apresenta grande parte de suas características originais ausentes, como granulometria, contatos, seleção, empacotamento, constituintes e matriz.

Macroscopicamente, os packstones intraclásticos $\left(\mathrm{N}_{6}, \mathrm{~N}_{4}, \mathrm{~N}_{3}\right)$ correspondem a níveis com porosidade macro 
e microscópica quase ausente ou muito pequena (máx. 5\%), suporte de grãos com granulomentria pobremente selecionada, variando de 0,15 a $2 \mathrm{~mm}$ (areia fina a muito grossa), e são formados por 20 a $25 \%$ de matriz micrítica. Os packstones do nível $\mathrm{N}_{6}$ diferem dos do nível $\mathrm{N}_{4}$ e $\mathrm{N}_{3}$ por apresentar menor proporção de cimento calcítico em mosaico (5\% contra $30 \%)$ e maior conteúdo de constituintes aloquímicos no primeiro (70\%) em comparação ao segundo (50\%) (Figuras 18A e 18B). Entre os constituintes aloquímicos do nível $\mathrm{N}_{6}$ predominam: $62 \%$ de intraclastos, $30 \%$ peloides, $5 \%$ foraminíferos miliolídeos, $2 \%$ bivalves e
$1 \%$ foraminíferos rotalinídeos. Enquanto no nível $\mathrm{N}_{4}, 70 \%$ são representados por intraclastos, $5 \%$ por peloides, $6 \%$ equinodermas, $10 \%$ bivalves, $3 \%$ algas verdes, $2 \%$ algas vermelhas, $2 \%$ foraminíferos miliolídeos, $1 \%$ briozoários e 1\% gastrópodes (Figura 19). Embora ambos sejam classificados como packstones intraclásticos segundo Dunham (1962), as diferenças descritas quanto à proporção de matriz predominantemente esparítica ou micrítica permitem classificar os carbonatos do nível $\mathrm{N}_{6}$ como intraesparitos e os do nível $\mathrm{N}_{4}$ como intramicritos, aplicando a classificação de Folk (1959). O processo diagenético pode ser definido
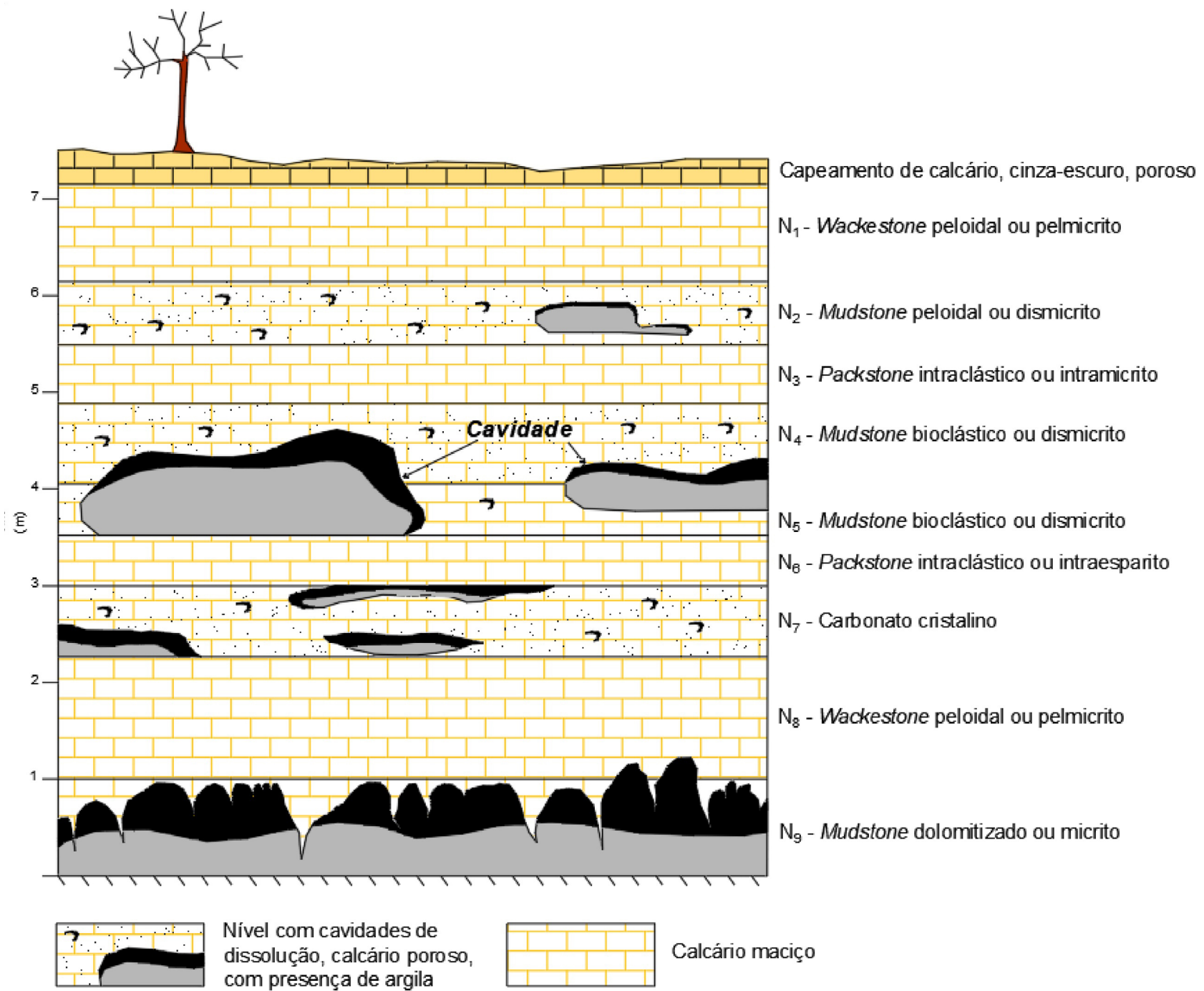

Nivel com cavidades de dissolução, calcário poroso, com presença de argila

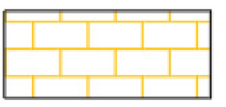

Calcário maciço

Figura 15. Desenho esquemático do comportamento do calcário em nove camadas identificadas, constituindo, ao todo, 7,5 m de altura, de acordo com a análise petrográfica de cada nível. Foram identificadas as seguintes variações faciológicas: mudstones, que representam os níveis de maior porosidade, facilmente solúveis, favoráveis ao desenvolvimento de cavernas $\left(\mathrm{N}_{9}, \mathrm{~N}_{5}, \mathrm{~N}_{2}\right)$; carbonato cristalino, resultado da recristalização do calcário formado essencialmente pela cimentação da calcita em mosaico $\left(\mathrm{N}_{7}\right)$; e wackestone e packstone, que representam o calcário maciço, que correspondem ao teto e à base daqueles facilmente solúveis $\left(\mathrm{N}_{1}, \mathrm{~N}_{3}, \mathrm{~N}_{8}\right)$. 

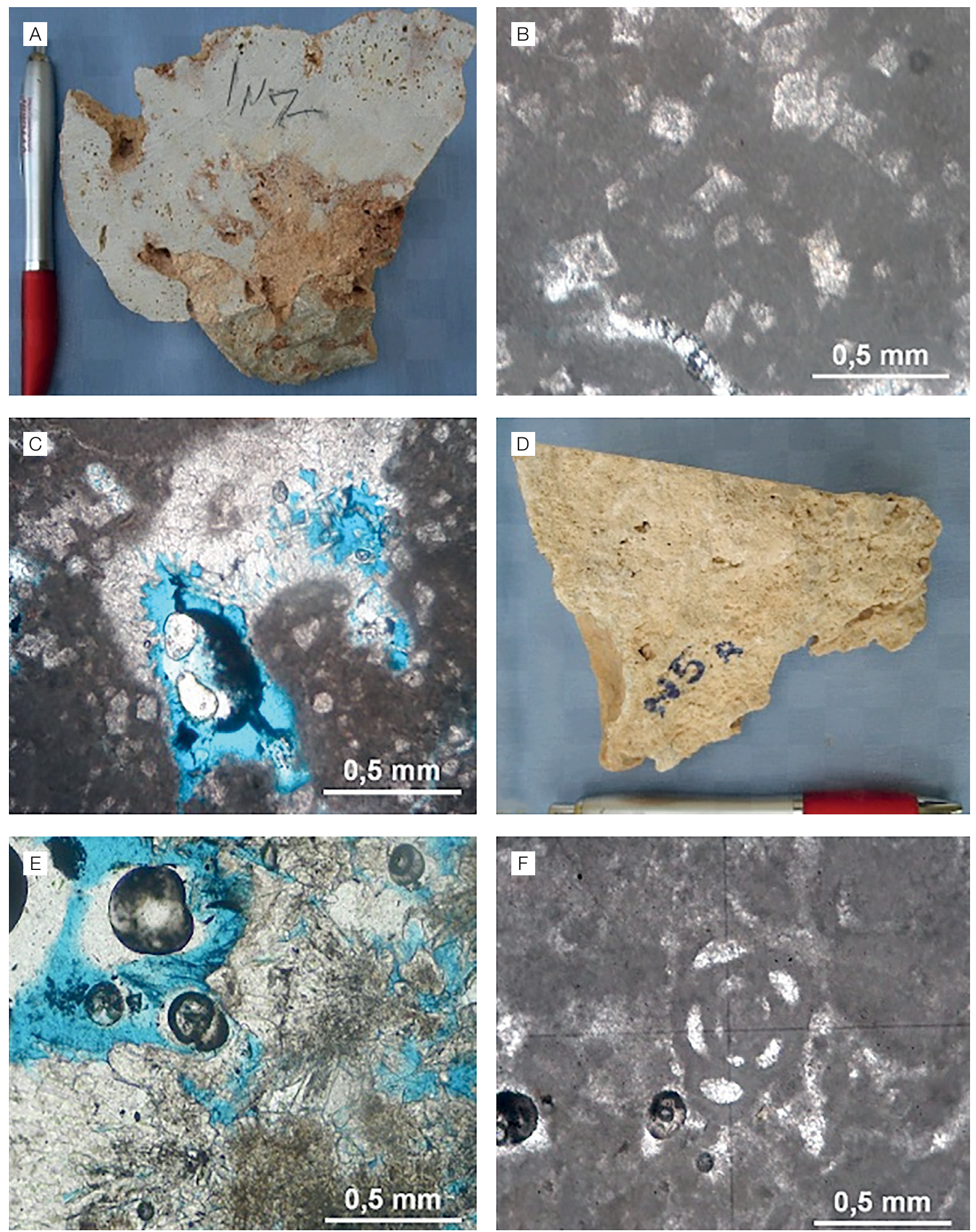

Figura 16. (A) Amostra de calcário no nível $\mathrm{N}_{2}$, ilustrando porções maciças do mudstone e regiões porosas intemperizadas preenchidas por material argiloso; (B) zonas recristalizadas e dolomitizadas; (C) presença de porovugs no cimento; (D) amostra de calcário creme-claro do nível $\mathrm{N}_{5}$, ilustrando porosidade secundária; (E) recristalização secundária de calcita e vugs; (F) foraminífero miliolídeo comumente encontrado entre os microfósseis marinhos que constituem as fácies do calcário Jandaíra. 

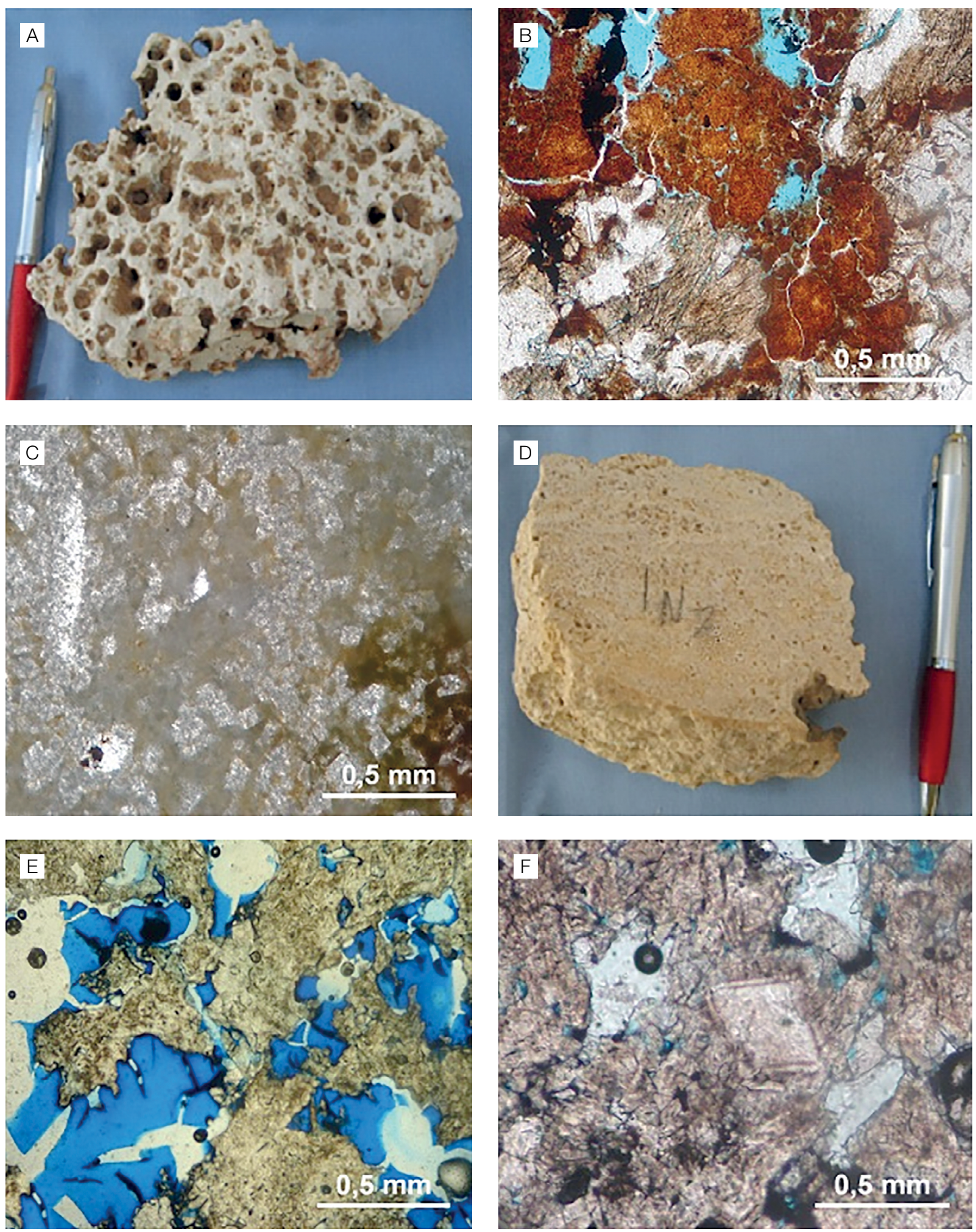

Figura 17. (A) Amostra de calcário do nível $\mathrm{N}_{\mathrm{o}}$, em que se encontra desenvolvida a maior parte da gruta de Arapuá; (B) restos de calcita espática associada a limonita, argila e formação de vugs; (C) processo diagenético de recristalização e dolomitização; (D) amostra de calcário poroso creme-amarelado do nível $\mathrm{N}_{7}$; (E) porosidade vugular em cimento de calcita em mosaico microcristalino; (F) dolomita isolada em cimento constituído de calcita com mosaico médio em amostra de carbonato cristalino do nível $\mathrm{N}_{7}$. 
da seguinte forma: micritização, seguida de compactação mecânica, cimentação em franja e de calcita em mosaico, neomorfismo de bioclastos, dolomitização e dissolução.

Os wackestones pelodais $\left(\mathrm{N}_{8} \mathrm{e} \mathrm{N}_{1}\right)$ são maciços, densos, de cor creme-clara, com pequenos cristais disseminados de calcita. Também é visível o processo de dissolução do calcário, embora bem menos intenso que nas camadas cavernosas, com poros localizados e preenchidos por material argiloso vermelho-amarelado. Ao microscópio, observa-se predomínio de matriz do tipo deposicional $(65 \%)$, cerca de $30 \%$ de constituintes aloquímicos e aproximadamente $5 \%$ de cimento, na forma de calcita microcristalina. Entre os aloquímicos predominam os peloides (cerca de $80 \%$ ) com tamanho médio de $0,10 \mathrm{~mm}$ sobre os intraclastos (20\%) (Figura 18C).
Com as análises petrográficas e observações de campo, nota-se que as rochas classificadas como mudstones são as que apresentam maior porosidade. Geralmente, evoluindo a partir do cimento calcíltico, facilmente solúvel, em todos os casos levando à formação de vugs, ou porosidade entre os grãos. Essas rochas representam os níveis cavernosos, associados a porções intemperizadas e oxidadas contendo material argiloso friável. Por outro lado, os wackestones e os packstones correspondem a níveis distintos intercalados com calcário maciço, representando o teto e a base dos níveis de mudstone e calcário cristalino, mais facilmente solúveis. Em seus diferentes níveis, desde a superfície até a profundidade de 7,5 m, os calcários Jandaíra apresentam diversas formas de porosidade: vugular ou intergrão, intragrão, ao longo de
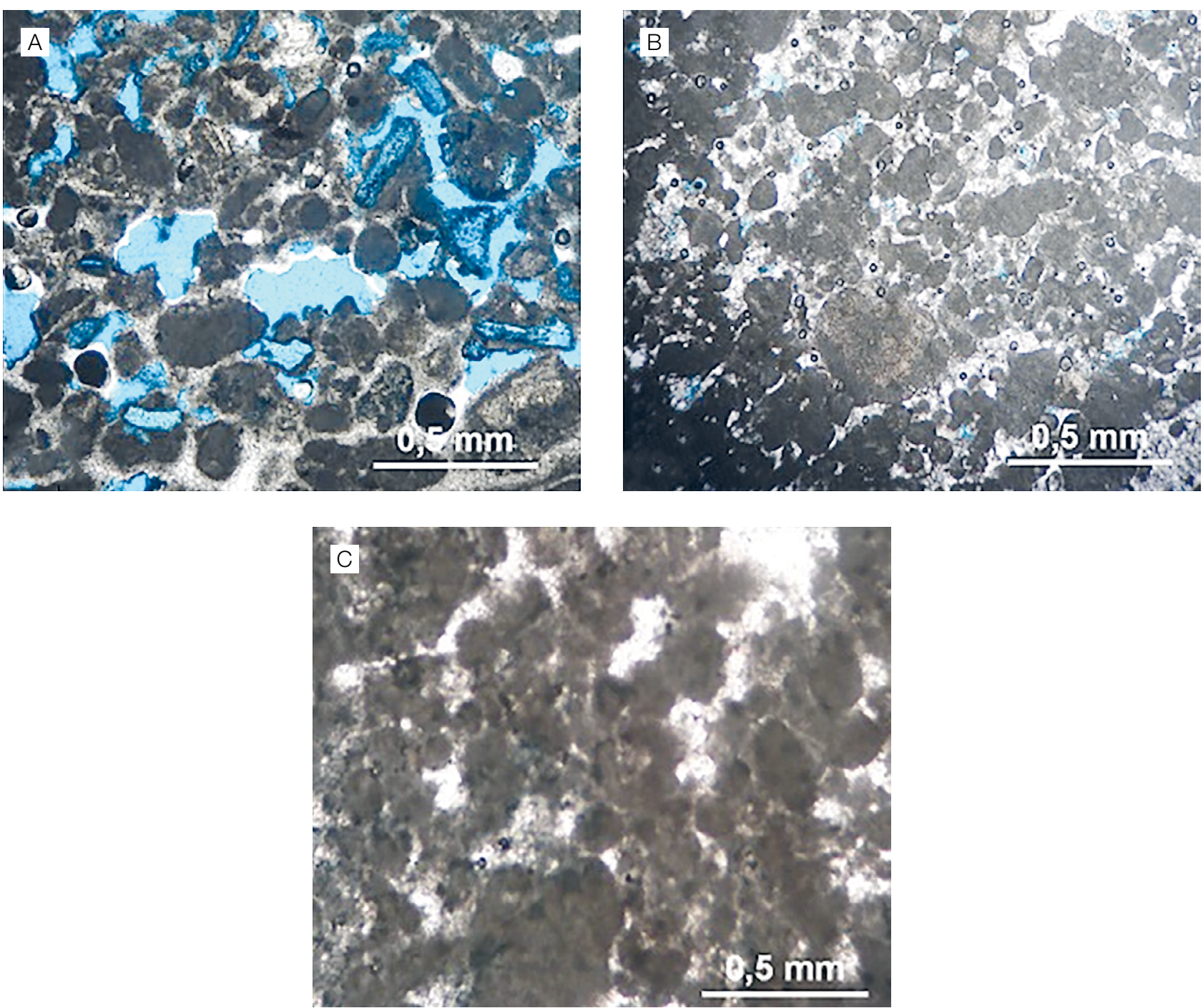

Figura 18. (A) Packstone intraclástico (Dunham, 1962) ou intramicrito (Folk, 1959) com porosidade intergrão ou entre peloides, envolvido por matriz micrítica incipiente; (B) packstone intraclástico (Dunham, 1962) ou intraesparito (Folk, 1959), representado por agregado de fragmentos líticos carbonáticos, com resquícios de porosidade entre os grãos; (C) wackestone peloidal (Dunham, 1962) ou pelmicrito (Folk, 1959) com peloides representando $80 \%$ de seus constituintes. 
estilólitos e em fraturas que servem de nucleadoras e ponto de partida para o desenvolvimento da macroporosidade, da ampliação e da formação de cavidades maiores (Figura 20).

\section{ESPELEOMETRIA}

Para a coleta de dados de subsuperfície, foi realizado o mapeamento espeleológico na escala 1:200 da caverna de Arapuá, localizada na porção leste do lajedo de mesmo nome. Essa caverna possui entrada principal vertical facilitada por uma árvore fixada em seu interior a cerca de $3 \mathrm{~m}$ da superfície, cuja copa se projetou acima do lajedo a partir de claraboia situada na parede oeste da galeria principal (Figura 21).

A caverna é composta por duas galerias, uma maior, com 54 $m$ de desenvolvimento linear, orientada NW-SE; e outra menor, de 33 m, com direção NE-SW. Internamente, observa-se um conjunto expressivo de espeleotemas (estalactites, estalagmites e outros escorrimentos) controlados por fraturas que se propagam a partir da superfície, por meio dos estratos da Formação Jandaíra (Figuras 22A e22B). Comparando as direções tomadas em seu interior, incluindo alinhamentos de estalactites e fendas no teto (Figura 22C), com aquelas medidas em superfície, observa-se a concentração de duas direções preferenciais no diagrama de roseta (NE-SW e NW-SE), que correspondem às direções aproximadas do desenvolvimento da caverna (Figura 21). Outro fato importante é a existência de estratos porosos associados aos níveis de maior desenvolvimento da caverna, os quais correspondem aos níveis de mudstone $\left(\mathrm{N}_{2}, \mathrm{~N}_{5}\right.$ e $\left.\mathrm{N}_{9}\right)$ (Figuras 22D e 22E). Em sua porção central, onde se localiza a entrada principal, ocorre desnível com inclinação de cerca de $45^{\circ}$ que conecta os níveis preferenciais de dissolução representados pelos mudstones peloidal $\left(\mathrm{N}_{2}\right)$ e bioclástico $\left(\mathrm{N}_{5}\right)$ com nível inferior de mudstone dolomitizado $\left(\mathrm{N}_{9}\right)$. A ausência de
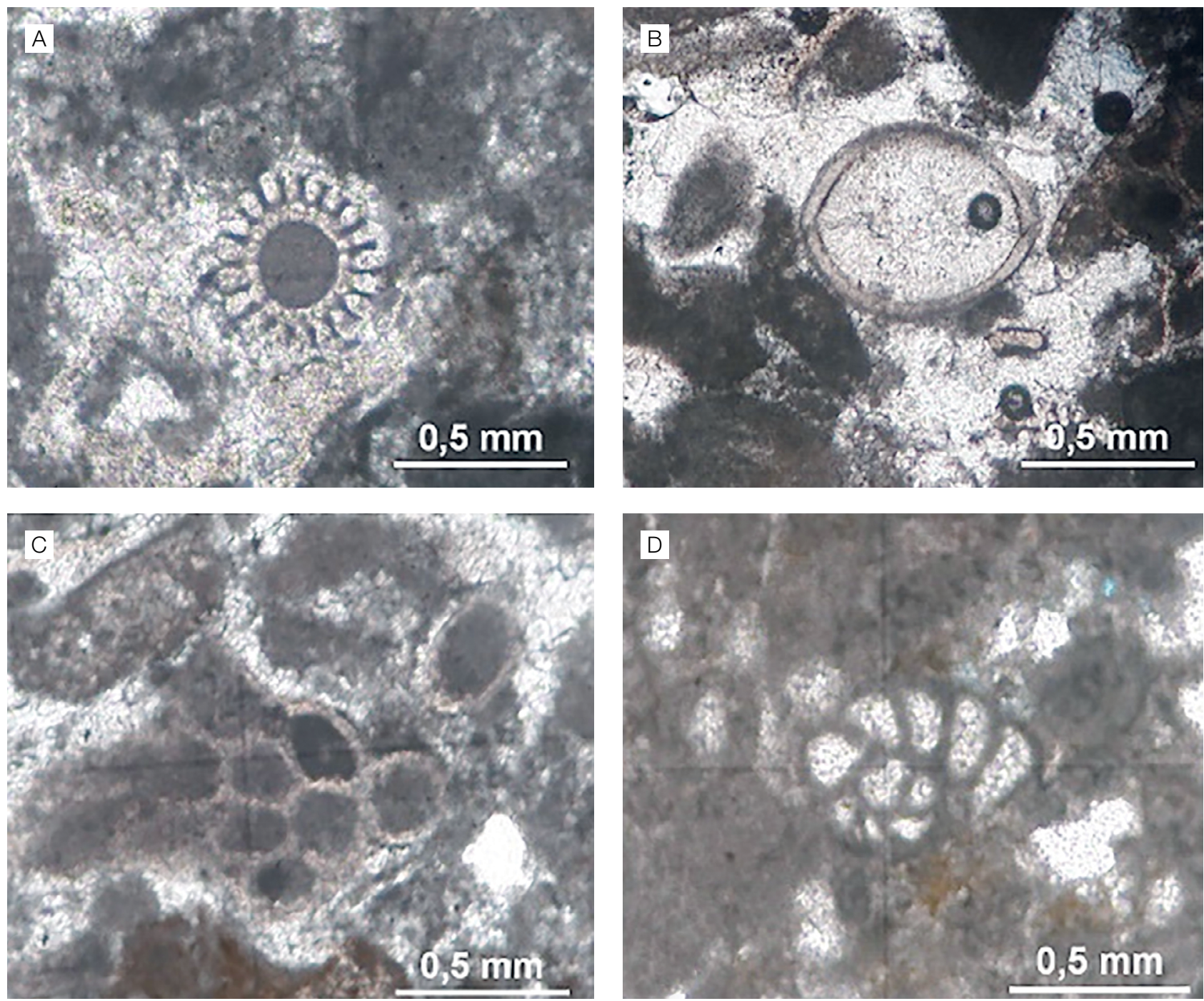

Figura 19. Registros fósseis representados por equinodermas (A), bivalves (B), briozoários (C) e foraminífero rotalinídeo (D). 

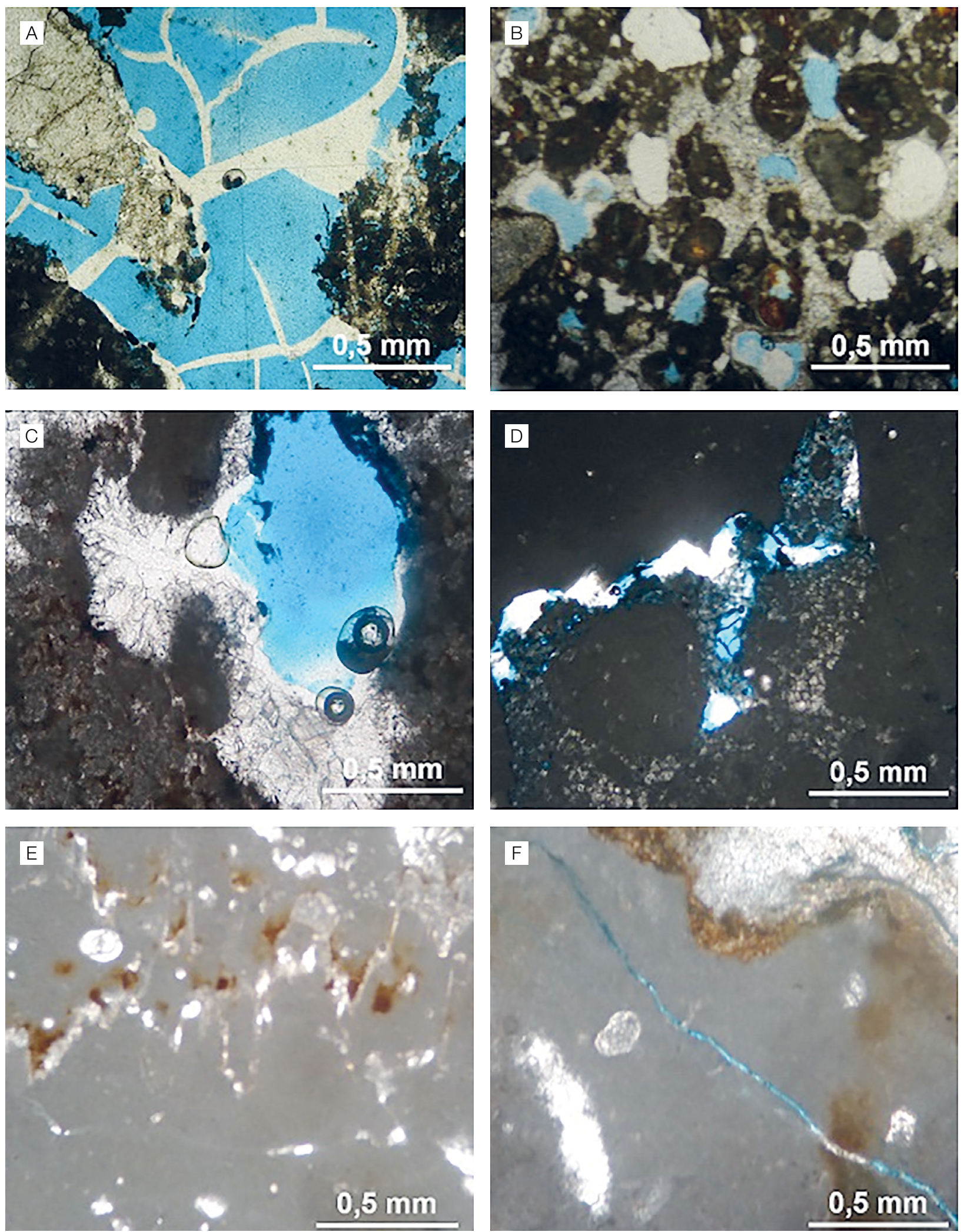

Figura 20. Tipos de porosidade presentes nos mudstones e nos calcários cristalinos $\left(N_{9}, N_{7}, N_{5}, N_{2}\right)$; (A) vugular em cimento de calcita microcristalina; (B) intergrão; (C) vugular em cristais de calcita espática; (D) em estilólito poroso; (E) em estilólito oxidado; (F) em fratura. 


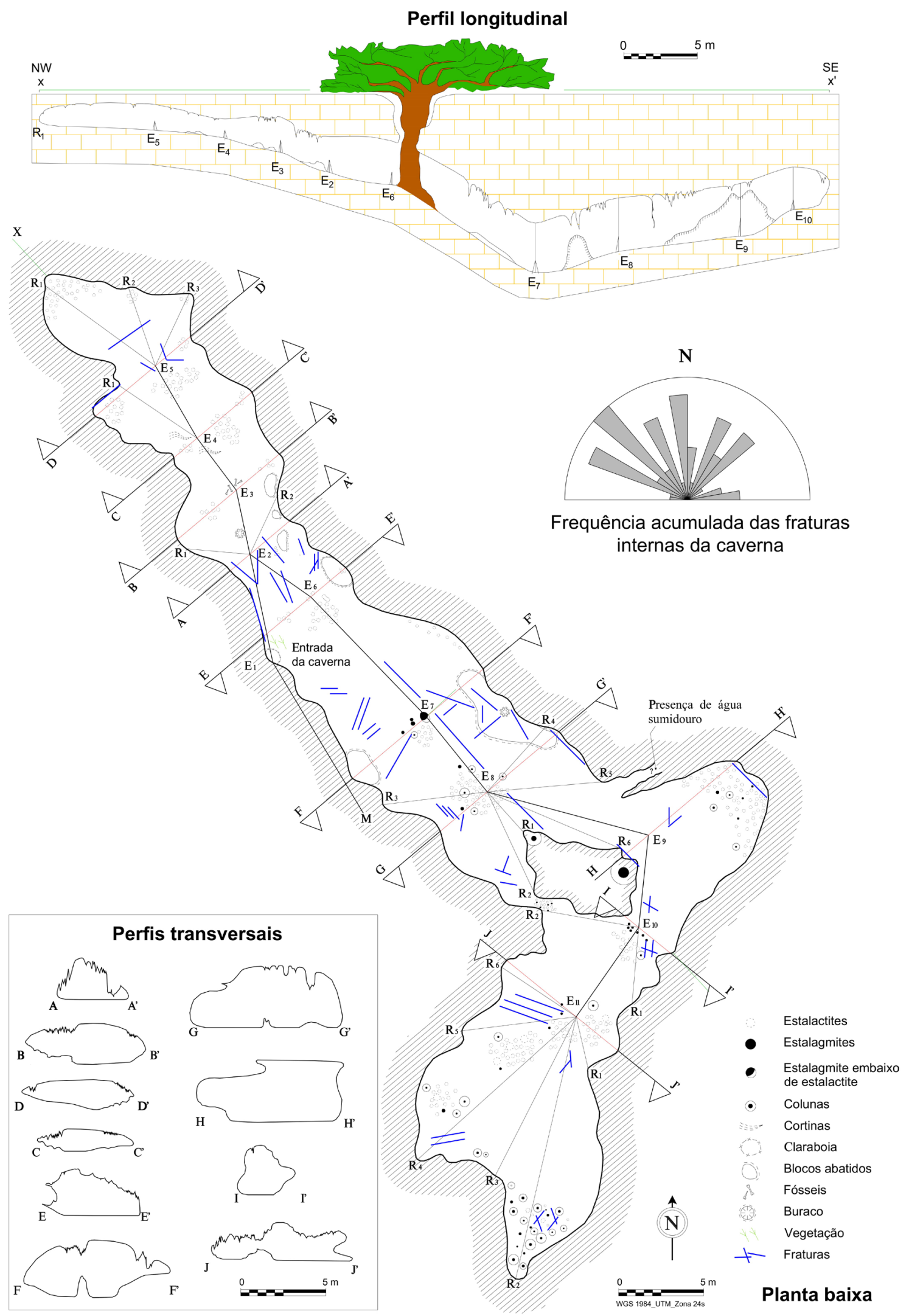

Figura 21. Topografia da caverna, com diagrama de roseta mostrando a frequência acumulada das fraturas internas e externas da caverna. 
continuidade visível dos níveis porosos $\left(\mathrm{N}_{2}\right.$ e $\left.\mathrm{N}_{5}\right)$ na porção sudeste da caverna, acima do nível $\mathrm{N}_{9}$, pode sugerir variação faciológica lateral na escala mapeada ou dissolução preferencial no sentido transversal à seção longitudinal, segundo direção NE, conforme sugerido pelo sumidouro ativo presente na cota mais baixa da gruta (Figura 21A).

A geometria semicircular ou elipsoidal da maioria das seções transversais, com o maior eixo segundo o plano de acamamento sedimentar, sugere a influência da estratificação nos processos de dissolução em condições freáticas. Por outro lado, a retilineidade de paredes e galerias, especialmente observada na porção central da caverna junto ao controle do atual sumidouro ativo na direção nordeste, mostra a influência das estruturas rúpteis na dissolução, ainda em condições freáticas. As direções NE-SW e NE-SW das galerias e a geometria das seções E-E', H-H' e G-G' na planta baixa da gruta de Arapuá ilustram, em parte, o citado controle estrutural (Figura 21A).

A comparação entre as direções das descontinuidades presentes no interior da gruta com as levantadas na superfície do lajedo mostra a influência das fraturas na gênese e na morfologia da caverna de Arapuá, uma vez que a direção de suas galerias coincide com a orientação da maior parte das juntas e das falhas da área e com o trend estrutural regional, onde predominam as estruturas com direções NW-SE e NE-SW. Essa influência ocorreu nas fases inicias da formação da caverna, em condições freáticas, e continuou na fase vadosa, conforme se pode observar pelo alinhamento de estalactites, estalagmites e zonas de infiltração atualmente observadas no interior da caverna.

\section{CONCLUSÕES}

O levantamento e a análise dos parâmetros orientação, persistência, abertura e profundidade das descontinuidades presentes no exocarste e no endocarste, juntamente com estudos petrográficos dos diferentes estratos carbonáticos, permitiram definir os principais condicionantes da carstificação e da geração de cavernas no lajedo de Arapuá.

Nesse setor da Bacia Potiguar, centro leste do município de Felipe Guerra, o arranjo estrutural das descontinuidades mostra a existência de quatro famílias de fraturas preferenciais, com direções NW-SE, NE-SW, N-S e E-W.

Nos modelos matemáticos de simulação estocástica booleana aplicados aos parâmetros orientação espacial e profundidade das estruturas mapeadas, observa-se a diminuição da penetratividade das estruturas E-W e N-S com a profundidade e reforça a tendência de propagação em subsuperfície das estruturas NW-SE e NE-SW. Esse fato, somado às observações e às medidas no interior da gruta de Arapuá, confirma a influência do controle das fraturas NW-SE e NE-SW na gênese da caverna.
Algumas feições indicativas da influência do controle estratigráfico nos processos de dissolução em condições freáticas incluem:

- a geometria semicircular e elíptica das galerias com maior desenvolvimento segundo o eixo maior paralelo ao acamamento sedimentar;

- a existência de horizontes carbonáticos com maior porosidade vugular representados por níveis de mudstones e calcários cristalinos associados às zonas de maior desenvolvimento e ampliação lateral das galerias.

Feições que denotam o controle estrutural, ainda em condições freáticas, são:

- a retilineidade das galerias na mesma direção preferencial de fraturas penetrativas existentes no lajedo carbonático;

- a existência de seções transversais na gruta de Arapuá com paredes laterais verticais;

- o sumidouro ativo encaixado em fratura de direção NE.

Outra feição importante que denota o controle estrutural em condições vadosas consiste na coincidência entre as zonas de infiltração e os planos de fraturas que se propagam da superfície ao interior da gruta de Arapuá, condicionando o alinhamento de estalactites e estalagmites, assim como outras zonas de escorrimento e percolação de águas superficiais.

Face o exposto, pode-se concluir que a dissolução e a circulação das águas no lajedo de Arapuá seguiram controle geológico relacionado à faciologia original das rochas carbonáticas e também controle estrutural - este condicionado pela existência de estruturas pretéritas que se alargaram pela ação de águas acidificadas dissolvendo o carbonato de cálcio, influenciando na geometria das galerias subterrâneas da gruta de Arapuá. Fenômenos de abatimento e ampliação dos espaços na transição da fase freática e em condições francamente vadosas somaram-se localmente aos processos citados.

As direções das principais galerias que configuram a gruta estudada e as estruturas rúpteis mapeadas na superfície do lajedo coincidem com as dos principais sistemas de falhas extensionais que configuram a geometria de altos e baixos estruturais orientados segundo as direções NE-SW e NW-SE, herdados da formação da Bacia Potiguar durante a abertura do oceano Atlântico Sul.

Evidências de atuação de tectonismo cenozoico afetando a sequência carbonática pós-rifte da Bacia foram constatadas pela observação de juntas estilolíticas ligadas à dissolução sob pressão, perpendiculares à estratificação, coerente com tensões compressivas horizontais atribuídas por outros autores à reativação de falhas extensionais em regime transcorrente. Tais evidências podem sugerir a influência de atuação do campo de tensões neotectônico na gênese de parte dos processos de carstificação no lajedo de Arapuá e em outras exposições de rochas carbonáticas na Bacia Potiguar, os quais precisam ser melhor estudados. 

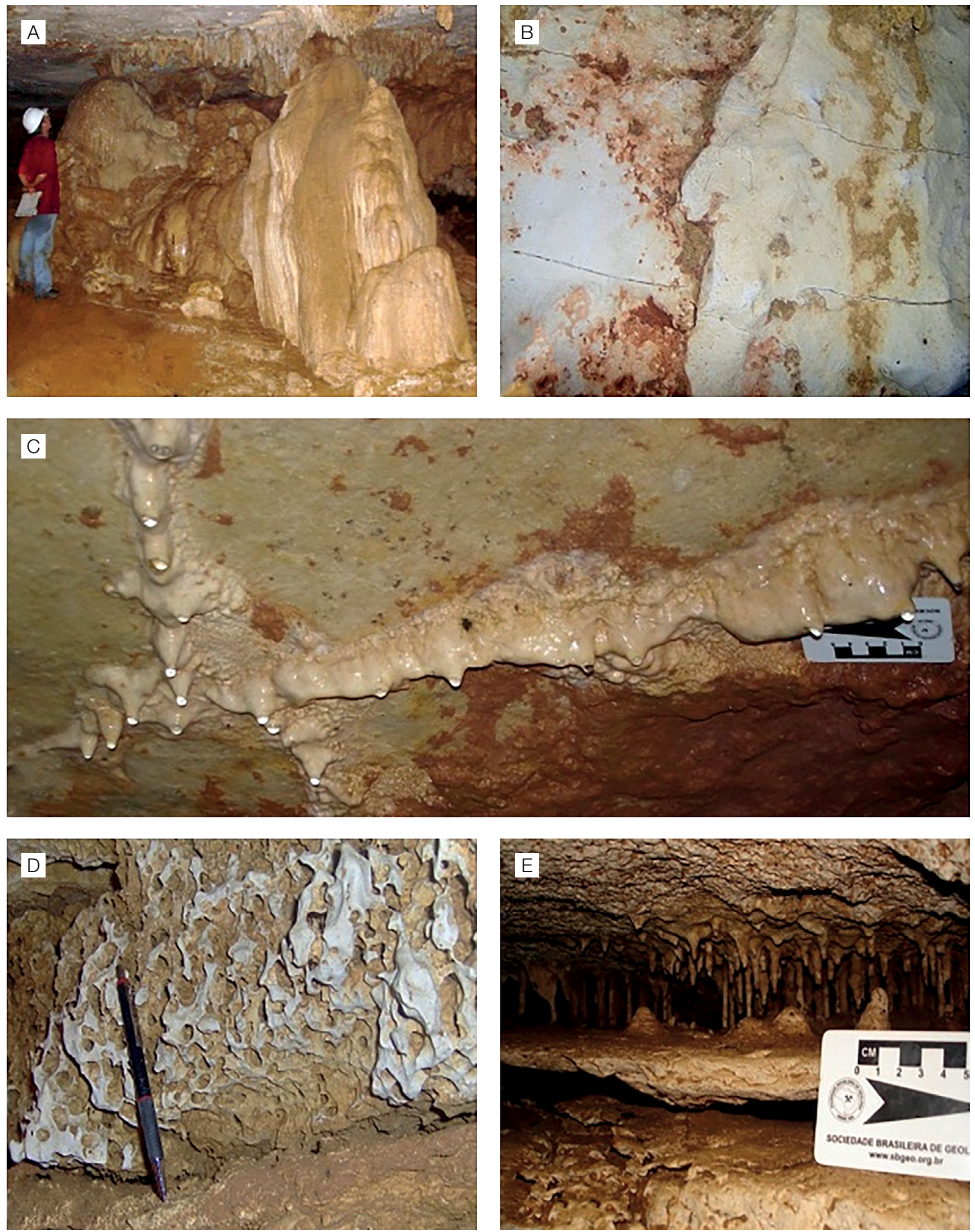

Figura 22. (A) Cortinas estalactíticas e maciço estalagmítico com cerca de $7 \mathrm{~m}$ de comprimento condicionados por fratura NW-SE que controla o desenvolvimento da galeria mais extensa de Arapuá; (B) sistema de fraturas NE-SW e NW-SE no interior da caverna; (C) estalactites em processo de formação controladas por gotejamento em fendas no teto de direção NE-SW e NW-SE; (D) e (E) estratos porosos associados, respectivamente, aos níveis $\mathrm{N}_{9}$ (mudstone dolomitizado) e $\mathrm{N}_{5}$ (mudstone bioclástico). 


\section{AGRADECIMENTOS}

Aos Departamentos de Geologia da UFC e da UFRN, a infraestrutura laboratorial disponibilizada para a realização desta pesquisa. Ao Conselho Nacional de Desenvolvimento Científico e Tecnológico (CNPq), o apoio financeiro por meio da concessão de bolsa de Mestrado institucional. À empresa Carbomil Química S/A, as análises químicas. Agradecemos, ainda, aos professores Geovan Tavares e Hélio Lopes (PUC-Rio), a modelagem estocástica, que serviu para a dissertação de mestrado da primeira autora, defendida em 2008, na UFC; e à Agência Nacional do Petróleo, Gás Natural e Biocombustíveis (ANP), a cessão de dados para publicação.

\section{REFERÊNCIAS}

Almeida, F. F. M., Carneiro, C. D. R., Machado Jr., D. L., Dehira, L. K. (1988). Magmatismo pós-paleozoico no nordeste oriental do Brasil. Revista Brasileira de Geociências, 18(4), 451-462. https://doi.org/10.25249/0375-7536.1988451462

Angelim, L. A. A. (2006). Geologia e recursos minerais do Estado do Rio Grande do Norte - Escala 1:500.000. Recife: CPRM - Serviço Geológico do Brasil, 119 p.

Bento, D. M., Cruz, J. B., Ferreira, R. L., Veríssimo, C. U., Xavier Neto, P. (2011). Mapeamento, caracterização ambiental e relevância do patrimônio espeleológico de Felipe Guerra/ RN. XXXI Congresso Brasileiro de Espeleologia, Anais, 485-564. Ponta Grossa: SBE.

Bertani, R. T., Costa, I. G., Matos, R. M. D. (1990). Evolução tectono-sedimentar, estilo estrutural e hábitat do petróleo na Bacia Potiguar. In: G. P. Raja Gabaglia, E. J. Milani (Eds.). Origem e evolução de bacias sedimentares (291-310). Rio de Janeiro: Petrobras, SEREC, CENSUD.

Bezerra, F. H. R. (2000). Neotectonic movements in northeastern Brazil: implications for a preliminary seismic-hazard assessment. Revista Brasileira de Geociências, 30(3), 562-564. https://doi.org/10.25249/0375-7536.2000303562564

Bezerra, F. H. R., Amaro, V. E., Vita-Finzi, C., Saadi, A. (2001). Pliocene-Quaternary fault control of sedimentation and coastal plain morphology in NE Brazil. Journal of South American Earth Sciences, 14(1), 61-75. https://doi. org/10.1016/s0895-9811(01)00009-8

Bezerra, F. H. R., Nascimento, A. F., Ferreira, J. M., Nogueira, F. C., Fuck, R. A., Brito Neves, B. B., Sousa, M. O. L. (2011). Review of active faults in the Borborema Province,
Intraplate South America Integration of seismological and paleoseismological data. Tectonophysics, 510(3-4), 269-290. https://doi.org/10.1016/j.tecto.2011.08.005

Bezerra, F. H. R., Neves, B. B. B., Corrêa, A. C. B., Barreto, A. M. F., Suguio, K. (2008). Late Pleistocene tectonicgeomorphological development within a passive margin - the Cariatá trough, northeastern Brazil. Geomorphology, 97(3-4), 555-582. https://doi.org/10.1016/j.geomorph.2007.09.008

Bezerra, F. H. R., Silva, F. O., Sousa, M. O. L., Amaral, R. F., Fonseca, V. P., Vieira, M. M., Moura-Lima, E. N. (2006). Mapeamento Geológico da Folha Macau (SB-24-X-D-II). Escala. 1:100.000. Programa Geologia do Brasil - PGB. Recife: CPRM/UFRN.

Bezerra, F. H. R., Takeya, M. K., Sousa, M. O. L., Nascimento, A. F. (2007). Coseismic reactivation of the Samabaia fault, Brazil. Tectonophysics, 430(1-4), 27-39. https://doi. org/10.1016/j.tecto.2006.10.007

Bezerra, F. H. R., Vita-Finzi, C. (2000). How active is a passive margin? Paleoseismicity in northeastern Brazil. Geology, 28(7), 591-594. https://doi.org/10.1130/0091-7613(2000)28<591:hai apm>2.0.co;2

Burrough, P. A., McDonnell, R. A. (1998). Principles of geographical information systems. Oxford: Oxford University Press, 333 p.

Carneiro, M. A., Bezerra, F. H. R., Silva, C. C. N., Maia, R. P., Cazarin, C. L. (2015). Controle estrutural do sistema cárstico epigenético na formação Jandaíra, Bacia Potiguar. Revista de Geociências, São Paulo, 34(2), 199-209.

Chang, H. K., Kowsmann, R. O., Figueiredo, A. M. F., Bender, A. A. (1992). Tectonics and stratigraphy of the East Brazil rift system: an overview. Tectonophysics, 213(1-2), 97-138. https://doi.org/10.1016/0040-1951(92)90253-3

Cremonini, O. A. (1993). Caracterização estrutural e evolução da área de Ubarana, porção submersa da Bacia Potiguar, Brasil. Dissertação (Mestrado). Ouro Preto: Departamento de Geologia - UFOP.

Cruz, J. B., Bento, D. M., Bezerra, F. H. R., Freitas, J. I., Campos, U. P., Santos, D. J. (2010). Diagnóstico Espeleológico do Rio Grande do Norte. Revista Brasileira de Espeleologia, 1(1), 1-24.

Dantas, E. P. (1998). Gravimetria e Sensoriamento Remoto: uma aplicação ao estudo da tectônica recente entre Macau e São Bento do Norte. Dissertação (Mestrado). Natal: Centro de Ciências Exatas e da Terra - UFRN. 
Dunham, R. J. (1962). Classification of Carbonate Rocks According to Depositional Texture 1. In: W. E. Ham (Ed.). Classification of carbonate rocks: memoirs (1, 108-121). Estados Unidos: American Association of Petroleum Geologists.

Ferreira, J. M., Oliveira, R. T., Takeya, M. K., Assumpção, M. (1998). Superimposition of local and regional stresses in northeast Brazil: evidence from focal mechanisms around the Potiguar marginal basin. Geophysical Journal International, 134(2), 341-355. https://doi.org/10.1046/j.1365-246x.1998.00563.x

Folk, R. L. (1959). Practical petrographic classification of limestones. AAPG Bulletin, 43, 1-38. https://doi. org/10.1306/0bda5c36-16bd-11d7-8645000102c1865d

Ford, D., Williams, P. (1989). Karst Hydrology and Geomorphology. Chichester: John Wiley \& Sons.

Françolin, J. B. L., Szartmari, P. (1987). Mecanismo de rifteamento da porção oriental da margem norte brasileira. Revista de Geociências, São Paulo, 17(2), 196-207.

Hackspacher, P. C., Corsino, A. R., Srivastava, N. K., Tiriba, V. F. (1985). A Falha de Afonso Bezerra como evidência de significativo tectonismo frágil NW-SE, na Bacia Potiguar emersa - RN. Boletim do Departamento de Geologia/UFRN, Natal, 10, 33-44.

Instituto de Desenvolvimento Econômico e Meio Ambiente (IDEMA). (2005). Anuário Estatístico do Rio Grande do Norte. Disponível em: $<$ http://www.idema.rn.gov.br $>$. Acesso em: 17 nov. 2006.

International Society for Rock Mechanics (ISRM). (1983). Método para descrição quantitativa de descontinuidades em maciços rochosos. Tradução de: ISRM (1878). Suggested methods for the quantitative description of discontinuities in rock masses. São Paulo: ABGE/CBRM, 132 p. (Trad. 12).

Lanzarini, W. L., Poletto, C. A., Tavares, G., Pesco, S., Lopes, H. (1997). Stochastic modeling of geometric objects and reservoir heterogeneites. SPE 5th Latin American and Caribbean Petroleum Engineering Conference, Paper SPE 38953. Rio de Janeiro: SPE. https://doi. org/10.2118/38953-ms

Lantuéjoul, C. (1995). Random Sets and Functions - From Models to Conditional Simulation. 141p. (Course Notes).

Maia, R. P. (2012). Geomorfologia e neotectônica na Bacia Hidrográfica do Rio Apodi-Mossoró, NE do Brasil. Tese (Doutorado). Natal: Departamento de Geologia - UFRN.

Maia, R. P., Bezerra, F. H. R. (2012). Geomorfologia e neotectônica da Bacia Hidrográfica do Rio Apodi-Mossoró NE/Brasil. Mercator - Revista de Geografia da UFC, 11(24), 209-228. https://doi.org/10.4215/rm2012.1124.0013

Maia, R. P., Bezerra, F. H. R. (2013). Tectônica pós-miocênica e Controle Estrutural de Drenagem no Rio Apodi-Mossoró, Nordeste do Brasil. Boletim Geográfico, Maringá, 31(2), 57-68. https://doi.org/10.4025/bolgeogr.v31i2.18697

Maia, R. P., Bezerra, F. H. R. (2014). Condicionamento estrutural do relevo no nordeste setentrional brasileiro. Mercator - Revista de Geografia da UFC, 13(1), 127-141. https://doi.org/10.4215/rm2014.1301.0010

Matos, R. M. D. (1992). The Northeast Brazilian Rift System. Tectonics, 11(4), 766-791. https://doi.org/10.1029/91tc03092

Mendelson, E. (1977). Álgebra booleana e circuitos de chaveamento. Nova York: McGraw-Hill, 283 p.

Mizusaki, A. M. P., Thomaz-Filho, A., Milani, E. J., Césero, P. (2002). Mesozoic and Cenozoic igneous activity and its tectonic control in northeastern Brazil. Journal of South American Earth Sciences, 15(2), 183-198. https://doi. org/10.1016/s0895-9811(02)00014-7

Moraes Neto, J. M. (2003). Expressão sísmica da deformação frágil pós-Mioceno na Bacia Potiguar submersa, Nordeste do Brasil. IX Simpósio Nacional de Estudos Tectônicos, 274, Búzios: SBG.

Moura-Lima, E. N., Sousa, F. H. R., Bezerra, F. H. R., Castro, D. L., Damascena, R. V. C., Vieira, M. M., Legrand, J. M. (2011). Reativação cenozoica do sistema de falhas de Afonso Bezerra, Bacia Potiguar. Geociências, São Paulo, 30(1), 77-93.

Nogueira, F. C. C. (2004). Método Ground Penetrating Radar (GPR) e Análise Estrutural Aplicados ao Estudo da Geometria Tridimensional de Estruturas Cenozóicas na Bacia Potiguar. Dissertação (Mestrado). Fortaleza: Departamento de Geologia - UFC.

Nogueira, F. C. C., Bezerra, F. H. R., Castro, D. L. (2006). Deformação rúptil em depósitos da Formação Barreiras na porção leste da Bacia Potiguar. Geologia USP. Série Cientifica, 6(2), 51-59. https://doi.org/10.5327/ s1519-874x2006000300007 
Oliveira, D. C. (1993). O papel do Enxame de Diques Rio Ceará-Mirim na evolução tectônica do nordeste oriental (Brasil): implicações na formação do Rifte Potiguar. Dissertação (Mestrado). Ouro Preto: Departamento de Geologia - UFOP.

Palmer, A. N. (2007). Cave Geology. Dayton, Ohio: Cave Books.

Pessoa Neto, O. C. (2003). Estratigrafia de Seqüências da Plataforma Mista Neogênica na Bacia Potiguar, Margem Equatorial Brasileira. Revista Brasileira de Geociências, 33(3), 263-278. https://doi.org/10.25249/0375-7536.2003333263278

Poletto, C. A. (1996). Modelagem geológica orientada a objetos e simulação estocástica da geometria de reservatórios fluviais. Dissertação (Mestrado). Campinas: Instituto de Geociências - UNICAMP.

Projeto Água Subterrânea no Nordeste do Brasil (Proasne). (2006). Modelamento Matemático da Área de Recarga do
Aqüifero Açu. Rio Grande do Norte. Disponível em: <http:// proasne.net/acufinalreporte.html>. Acesso em: 23 nov. 2008.

Reis, A. F. C., Bezerra, F. H. R., Ferreira, J. M., Nascimento, A. F., Lima, C. C. (2013). Stress magnitude and orientation in the Potiguar Basin, Brazil: Implications on faulting style and reactivation. Journal of Geophysical Research: Solid Earth, 118(10), 5550-5563. https://doi. org/10.1002/2012jb009953

Santos, J. L. (2015). Controle estrutural e faciológico na espeleogênese em calcários da formação Jandaíra (Bacia Potiguar): Lajedo do Rosário, município de Felipe Guerra $-R N$. Tese (Doutorado). Fortaleza: Departamento de Geologia - UFC.

Sousa, M. O. L., Bezerra, F. H. R., Aquimo, M. R. (2005). Reativação de falhas sísmicas associadas à alta pressão de fluidos nas regiões de João Câmara e São Rafael - RN. X Simpósio Nacional de Estudos Tectônicos, 155-157, Curitiba: SBG. 